José Vida Fernández ${ }^{1}$

\title{
El desarrollo del sistema para la autonomía y atención a la dependencia en un contexto internacional: los compromisos derivados de la Convención sobre los derechos de las personas con discapacidad y de la pertenencia a la Unión Europea
}

SUMARIO: I. INTRODUCCIÓN. II EL SISTEMA PARA LA AUTONOMÍA Y LA ATENCIÓN A LA DEPENDENCIA ANTE LOS COMPROMISOS INTERNACIONALES: LA INCIDENCIA DE LA CONVENCIÓN INTERNACIONAL SOBRE LOS DERECHOS DE LAS PERSONAS CON DISCAPACIDAD. 1. ANÁLISIS DEL MARCO NORMATIVO INTERNACIONAL RELEVANTE EN LA APROBACIÓN DE la Ley 39/2006, de Promoción de la Autonomía y Atención a las personas EN SITUACIÓN DE DEPENDENCIA. 1.1. La atención a la dependencia en el ámbito de la Organización de Naciones Unidas. 1.2. La atención de la dependencia en el marco del Consejo de Europa. 1.3. Valoración del marco internacional y comparado en su relación con la politica sobre la dependencia en España. 2. LA INCIDENCIA DE LA CONVENCIÓN DE LOS DERECHOS DE LAS PERSONAS CON DISCAPACIDAD EN EL DESARROLLO Y APLI-

${ }^{1}$ Profesor Titular de Derecho Administrativo. Universidad Carlos III de Madrid. 
CACIÓN DE LA LEY 39/2006, DE PROMOCIÓN DE LA AUTONOMÍA Y ATENCIÓN A LAS PERSONAS EN SITUACIÓN DE DEPENDENCIA. 2.1. El significado de la Convención y la conexión de su contenido con la LPAP. 2.2. El contenido de la Convención relativo a la autonomía e independencia individual. 2.3. Objetivo y alcance de las obligaciones de la Convención con respecto a la promoción de la autonomía y la atención a la dependencia. 2.4. Concreción de las obligaciones dispuestas por la Convención con respecto a la promoción a la autonomía y la atención a la dependencia. 2.5. Valoración del cumplimiento de las obligaciones relativas al derecho a la vida independiente. III. EL SISTEMA PARA LA AUTONOMÍA Y ATENCIÓN A LA DEPENDENCIA EN EL DESARROLLO DEL PROCESO DE INTEGRACIÓN COMUNITARIA DE LA UNIÓN EUROPEA. 1. LA EVOLUCiÓN DE LAS MEDIDAS RELATIVAS A LA DEPENDENCIA EN EL PROCESO DE INTEGRACIÓN COMUNITARIO-EUROPEO DE LA UNIÓN EUROPEA. 2. LA INCIDENCIA DE LA UNIÓN EUROPEA EN EL DESARROLLO Y APLICACIÓN DE LA DE LA LEY 39/2006 DE PROMOCIÓN DE LA AUTONOMÍA Y ATENCIÓN A LAS PERSONAS EN SITUACIÓN DE DEPENDENCIA. 2.1. La Directiva 2006/123/CE, relativa a los servicios en el mercado interior y su aplicación a los servicios sociales. 2.2. La adecuación de los servicios sociales a la normativa comunitaria europea sobre contratación pública y sobre competencia. 2.3. La sostenibilidad de la financiación pública de los sistemas de protección de la dependencia.

\section{INTRODUCCIÓN}

La atención a las personas en situación de dependencia y la promoción de su autonomía personal constituye en la actualidad uno de los principales retos de la política social de los países desarrollados. Así se afirma en la exposición de motivos de Ley 39/2006, de 14 de diciembre, de Autonomía Personal y Atención a la Dependencia (LEPA), lo que pone de manifiesto la existencia de un contexto internacional — demográfico, económico, político-social y, en lo que nos interesa jurídicoque ha llevado al reconocimiento de los derechos de las personas en situación de dependencia.

El presente trabajo se sitúa en dicha perspectiva supranacional, si bien no analiza los orígenes de la LEPA a nivel internacional y comunitario ni tampoco pretende enjuiciar su originalidad en comparación con las soluciones adoptadas en otros países. Estas cuestiones ya han sido suficientemente tratadas en diversos estudios e informes, por lo que ahora se pretende valorar en qué medida el contexto internacional y comunitario-europeo puede condicionar el desarrollo de la LEPA y su aplicación efectiva.

El interés que presenta el presente estudio reside en que la evolución del marco jurídico a nivel supranacional condiciona el desarrollo y la aplicación de la LEPA modulando la configuración del sistema público de protección de la dependencia y, por tanto, el contenido mismo del derecho a la promo- 
ción de la autonomía personal y a la atención de las situaciones de dependencia. Por lo tanto, los cambios dentro del marco internacional y comunitaria posteriores a la aprobación de la LEPA conllevan la necesidad de modificar o reajustar su contenido.

Por esta razón la finalidad del presente estudio consiste en analizar el marco jurídico existente en el momento de la elaboración y aprobación de la LEPA y, a partir del mismo comprobar las novedades relevantes y su eventual incidencia en el desarrollo y aplicación de la LEPA.

Para cumplir con dicho objetivo se hace necesario distinguir dentro de esta perspectiva supranacional - por razón de su distinto fundamento, naturaleza y alcance- entre el marco jurídico propio de las relaciones internacionales de cooperación y el referido a la proceso de integración comunitario-europeo.

Por esta razón, en primer lugar, se atenderá al tratamiento de la dependencia en el seno de dos de las organizaciones internacionales relevantes en este aspecto como son, a nivel global, la Organización de Naciones Unidas y, a nivel regional, el Consejo de Europa. Además de llevar a cabo un análisis de la influencia que desde estas dos instancias se ha ejercido en la elaboración de la LEPA (apartado 1.1. y apartado 1.2), se procede posteriormente a la valoración de dicha influencia (apartado 1.3). Por último, se analiza de forma específica la incidencia de la Convención sobre los Derechos de las Personas con Discapacidad de la ONU en el desarrollo de la LEPA (apartado 2).

En la segunda parte del trabajo se analiza el encaje de la LEPA en el proceso de integración comunitario-europeo dentro de la Unión Europea. Además de hacer un seguimiento del proceso europeo en el que se desarrolla nuestra política sobre dependencia hasta la aprobación de la LEPA (apartado 1), se realiza un análisis de la incidencia que el desarrollo del proceso de integración comunitario está teniendo en el desarrollo de la LEPA (apartado 2). En concreto, de la aplicación de la normas del mercado interior de servicios y, en particular, de la Directiva de Servicios (apartado 2.1.); de las normas de contratación pública y las normas sobre competencias (apartado 2.2.) y, por último, las obligaciones derivada del Pacto de Estabilidad (apartado 2.3).

Con este trabajo se pretende llamar la atención sobre la relevancia de las acciones de las instancias supranacionales para el desarrollo de los sistemas nacionales de protección social. Si bien cada Estado mantiene la competencia exclusiva sobre la configuración de sus respectivos sistemas, no cabe duda que éstos se encuentran expuestos a los compromisos internacionales y, en particular, a los comunitario-europeos que obligan a modular y adaptar su configuración. 


\section{EL SISTEMA PARA LA ATENCIÓN A LA AUTONOMÍA Y LA DEPENDENCIA ANTE LOS COMPROMISOS \\ INTERNACIONALES: LA INCIDENCIA DE LA CONVENCIÓN INTERNACIONAL SOBRE LOS DERECHOS DE LAS PERSONAS CON DISCAPACIDAD}

1. ANÁlisis DEL MARCo NORMATIVO INTERNACIONAL RELEVANTE EN LA elaboración de la Ley 39/2006, de Promoción de la Autonomía Y ATENCIÓN A LAS PERSONAS EN SITUACIÓN DE DEPENDENCIA

\subsection{La atención a la dependencia en el ámbito de la Organización de Naciones Unidas}

La cuestión de la autonomía personal y la atención a la dependencia no es novedosa. Si bien las soluciones adoptadas en cada país pueden resultar innovadoras, todas ellas afrontan una misma realidad que se viene manifestando desde siempre a nivel global. Se trata de la situación de las personas que por razón de sus condiciones psicofísicas, en relación con las circunstancias de la realidad en la que viven, requieren apoyo para el desarrollo de actividades básicas de la vida diaria.

Este hecho connatural a la vida en sociedad ha adquirido un significado propio en las últimas décadas para los países desarrollados al confluir dos circunstancias que han llevado a afrontarlo de forma sistemática e integral a través de políticas específicas. Se trata, por una parte, de unas determinadas condiciones socio-demográficas, que consisten en el incremento de la población en situación de dependencia (esencialmente por el envejecimiento y la mayor supervivencia ante la enfermedad o los accidentes) y la incorporación de la mujer al mundo laboral con la consiguiente desaparición del tradicional apoyo informal de base familiar; así como económicas, que han llevado a tratar de (re)incorporar a este colectivo a la población activa gracias a los avances en las tecnologías y servicios que permiten superar la situación de dependencia, que, a su vez, han generando un sector económico de creciente importancia. Por otra parte, la evolución política y social ha dado lugar a nuevas perspectivas en el tratamiento de esta situación, con el abandono de su tratamiento a partir del reconocimiento de derechos sociales prestacionales de configuración legal condicionados por la limitación de recursos y el reconocimiento final de la autonomía y la vida independiente como una cuestión de derecho humanos.

La creciente relevancia de la cuestión a nivel interno, en particular en los países desarrollados, llevó a plantearla a nivel internacional en el seno de los 
distintos organismos internacionales desde los que se han venido adoptando medidas de distinto significado y alcance ${ }^{2}$.

La propia LEPA deja traslucir en su exposición de motivos este contexto al afirmar que "el reconocimiento de los derechos de las personas en situación de dependencia ha sido puesto de relieve por numerosos documentos y decisiones de organizaciones internacionales, como la Organización Mundial de la Salud, el Consejo de Europa y la Unión Europea”. Resulta oportuno así entrar a considerar el alcance que el contexto internacional ha tenido en la configuración de la LEPA.

En el ámbito de la Organización de Naciones Unidas, las primeras actuaciones relativas a la dependencia se produjeron de forma fragmentada mediante el desarrollo de acciones a favor de los discapacitados y frente al envejecimiento de la población. La lentitud en la evolución de estas iniciativas se explica por las condiciones y limitaciones propias de la ONU en cuanto organización internacional de cooperación que desde 1945 viene desarrollando su actividad con alcance global desde una perspectiva territorial y material.

En el ámbito de la discapacidad ${ }^{3}$, tras diversas iniciativas aisladas ${ }^{4}$, en la década de los años setenta se inició una actuación sistemática dirigida a las personas con discapacidad. El reconocimiento de derechos mediante declaraciones genéricas constituyeron los primeros pasos antes de pasar a una acción mucho más extensa y concreta. Tanto la Declaración de los Derechos del Retrasado Mental, proclamada por la Asamblea General en su resolución 2856 (XXVI), de 20 de diciembre de 1971, así como la Declaración Universal de los Derechos del Impedido, proclamada por la Asamblea General en su resolución 3447 (XXX), de 9 de diciembre de 1975, vienen a reafirmar su dignidad así como los derechos civiles y políticos en los mismos términos que el resto de las personas y, asimismo, se proclama su derecho a

2 A la impronta internacionalista de la protección de la dependencia se ha referido V. Sempere Navarro; F. Cavas Martínez, Ley de Dependencia. Estudios de la Ley 39/2006, sobre promoción de la autonomía personal y atención a las personas en situación de dependencia, ThomsonAranzadi, Cizur Menor, 2007, pp. 17-19 y 25.

3 Una breve síntesis del desarrollo histórico de la discapacidad y la Naciones Unidas se puede encontrar en http://www.un.org/spanish/disabilities/default.asp?id=531

${ }^{4}$ En concreto del Consejo Económico y Social de las Naciones Unidas a través de su Resolución 309 E (XI) del Consejo Económico y Social de las Naciones Unidas, del 13 de julio de 1950, Rehabilitación Social de las personas físicamente impedidas; asimismo su Resolución 1086 E (XXXIX) del Consejo Económico y Social de las Naciones Unidas, del 30 de julio de 1965, sobre readaptación de los inválidos; y la Resolución 1921 (LVIII) del Consejo Económico y Social de las Naciones Unidas, del 6 de mayo de 1975, sobre prevención de la incapacitación y rehabilitación de los incapacitados. 
la autonomía personal, así como a la atención sanitaria, psicológica, y, en concreto, a la readaptación médica y social, reconociéndose asimismo el derecho a un nivel de vida adecuado en el seno familiar 5 .

Sin embargo, el reconocimiento de estos derechos se produce en términos generales, sin mandatos concretos y expresos a los Estados miembros. Así se aprecia en las medidas relativas a su aplicación ${ }^{6}$ en las que se limitó a recomendar a todos los Estados Miembros que tengan en cuenta los derechos y principios enunciados en la Declaración de los Derechos de los Impedidos al formular sus políticas, planes y programas; $y$, asimismo a todas las organizaciones y organismos internacionales interesados que prevean en sus programas disposiciones que garanticen la aplicación efectiva de esos derechos y principios.

En 1976 la ONU declaró, mediante Resolución 31/123 de su Asamblea General, el año 1981 como Año Internacional de los Impedidos con el objetivo de promover la participación y la igualdad de las personas con discapacidad mediante acciones preliminares dirigidas a identificar los obstáculos para su efectividad y a concienciar de dicha situación ${ }^{7}$. La única medida que se solicitaba fue la adopción de un plan de acción a nivel nacional, regional

5 En concreto, en la Declaración Universal de los Derechos del Impedido se reconoce que: "6. El impedido tiene derecho a recibir atención médica, psicológica y funcional, incluidos los aparatos de prótesis y ortopedia; a la readaptación médica y social; a la educación; la formación y a la readaptación profesionales; las ayudas, consejos, servicios de colocación y otros servicios que aseguren el aprovechamiento máximo de sus facultades y aptitudes y aceleren el proceso de su integración o reintegración social.

7. El impedido tiene derecho a la seguridad económica y social y a un nivel de vida decoroso. Tiene derecho, en la medida de sus posibilidades, a obtener y conservar un empleo y a ejercer una ocupación útil, productiva y remunerativa, y a formar parte de organizaciones sindicales.

8. El impedido tiene derecho a que se tengan en cuenta sus necesidades particulares en todas las etapas de la planificación económica y social.

9. El impedido tiene derecho a vivir en el seno de su familia o de un hogar que la substituya y a participar en todas las actividades sociales, creadoras o recreativas. Ningún impedido podrá ser obligado, en materia de residencia, a un trato distinto del que exija su estado o la mejoría que se le podría aportar. Si fuese indispensable la permanencia del impedido en un establecimiento especializado, el medio y las condiciones de vida en él deberán asemejarse lo más posible a los de la vida normal de las personas de su edad".

${ }^{6}$ Resolución 31/82 del 13 de diciembre de 1976, relativa a la Aplicación de la Declaración de los Derechos del Impedido

7 En su Resolución 31/123 la Asamblea pedía que se estableciera un plan de acción a nivel nacional, regional e internacional en el que se haga especial hincapié en la igualdad de oportunidades, la rehabilitación y la prevención de la discapacidad.

${ }^{\text {El }}$ Año tenía por lema "la plena participación y la igualdad", definidas como el derecho de las personas con discapacidad a participar plenamente en la vida y el desarrollo de su sociedad, a gozar de unas condiciones de vida similares a las de los demás ciudadanos, y a tener el mismo acceso a los beneficios derivados del desarrollo socioeconómico. 
e internacional en el que se haga especial hincapié en la igualdad de oportunidades, la rehabilitación y la prevención de la discapacidad.

A resultas de estas iniciativas se adoptó el Programa de Acción Mundial para Impedidos, aprobado por la Asamblea General mediante Resolución 37/52, de 3 de diciembre de 1982. Seguidamente tuvo lugar la Proclamación del Decenio de las Naciones Unidas para Impedidos (1983-1992) (Proclamado por la Asamblea General en el punto 11 de la resolución 37/53 del 03.12.82), como un plan de acción de largo plazo que no necesitará recursos adicionales del sistema de las Naciones Unidas para este propósito y que anima a los Estados Miembros a utilizar este período como un medio para implementar el Programa de Acción Mundial para Impedidos.

Tras el desarrollo del Programa de Acción Mundial durante toda esta década, éste se mantuvo mediante diversas resoluciones que lo llevaron hasta el año 2000 y años posteriores ${ }^{8}$. El desarrollo de este Programa conducía la iniciativas en el seno de la ONU y orientaba las políticas de los Estados. Sin embargo, desde las Declaraciones de los años setenta no se había producido ningún avance en la concreción de los derechos de las personas con discapacidad y, sobre todo, en las obligaciones de los Estados en la realización de estos derecho.

En esta línea, en 1987 se celebró en Estocolmo la Reunión Mundial de Expertos para examinar la marcha de la ejecución del Programa de Acción Mundial para los Impedidos, al cumplirse la mitad del Decenio de las Naciones Unidas para los Impedidos. En la Reunión se sugirió la necesidad de elaborar una doctrina rectora que indicase las prioridades de acción en el futuro, que debía basarse en el reconocimiento de los derechos de las personas con discapacidad. Sin embargo, no se alcanzó el consenso necesario para redactar una convención internacional sobre la eliminación de todas las formas de discriminación contra las personas con discapacidad.

Precisamente como alternativa se adaptaron unas "Normas Uniformes sobre la igualdad de oportunidades para las personas con discapacidad" por la Asamblea General de las Naciones Unidas en su cuadragésimo octavo período de sesiones, mediante resolución 48/96, del 20 de diciembre de 1993. Como se afirma en las mismas (apartado 14), si bien no son de cumplimiento obligatorio, se consideraba que estas Normas podían convertirse

El Año tiene también por objetivo incrementar la sensibilización de la opinión pública; comprender y aceptar a las personas con discapacidad; y alentar a las personas con discapacidad a constituir organizaciones que les permitan manifestar sus opiniones y promover la adopción de medidas encaminadas a mejorar su situación.

${ }^{8}$ Hacia una sociedad para todos: Estrategia a largo plazo para promover la aplicación del Programa de Acción Mundial para los impedidos hasta el Año 2000 y Años Posteriores (Anexo Doc. A/49/435). 
en normas internacionales consuetudinarias cuando las aplicasen un gran número de Estados con la intención de respetar una norma de derecho internacional. En el momento de su aprobación se consideró que esta normas llevaban implícito el firme compromiso moral y político de los Estados de adoptar medidas para lograr la igualdad de oportunidades y señalaban importantes principios de responsabilidad, acción y cooperación, destacando asimismo esferas de importancia decisiva para la calidad de vida y para el logro de la plena participación y la igualdad. Estas Normas se identifican como un instrumento normativo y de acción para personas con discapacidad y para sus organizaciones, que sientan las bases para la cooperación técnica y económica entre los Estados, las Naciones Unidas y otras organizaciones internacionales.

A partir de estas iniciativas, cuya aplicación ha sido objeto de seguimiento por parte de la Comisión de Desarrollo Social a través de un relator especial $^{9}$, desde comienzos de la década se ha promovido la elaboración de una Convención Internacional para proteger y promover los derechos y la dignidad de las personas con discapacidad (Resolución de la Asamblea General A/RES/56/168, de 19 de diciembre de 2001; Resolución del Consejo Económico y Social E/2002/INF/2/Add.2 del 24 de julio de 2002), creándose un Comité Especial encargado de preparar dicha convención (Resolución A/RES/57/229 del 18 de diciembre de 2002), cuyos trabajos desembocarían en la Convención Internacional de las Personas con Discapacidad de 2006 que será objeto de análisis específico más adelante.

Por otra parte, en el ámbito de acción frente al envejecimiento ${ }^{10}$, la ONU desarrollo medidas similares que parten de la década de los años setenta, cuando se proyectó la celebración de una conferencia mundial que tuvo lugar en 1982 en la que se aprobó el Plan de Acción Internacional sobre Envejecimiento ("Plan Viena”) adoptado mediante Resolución 37/51 de la Asamblea General de 1982. Al igual que en el Programa de Acción Mundial para Impedidos, este Plan establece unos criterios para guiar la actividad a nivel internacional así como las políticas de envejecimiento a nivel nacional, para dirigirlas hacia la consecución de una vida independiente de los mayores, a una mayor protección sanitaria y a una mejor coordinación entre servicios sanitarios y sociales.

9 El/La Relator/a de la Comisión de Desarrollo Social sobre discapacidad presenta informes anuales relativos a la vigilancia de la aplicación de las Normas Uniformes sobre la igualdad de oportunidades para las personas con discapacidad que son accesibles en http://www.un.org/ spanish $/$ disabilities $/$ default.asp?navid=9\&pid $=513$

${ }^{10}$ Con respecto a esta dimensión puede seguirse su evolución en Baviera Puig, I., La protección de la dependencia: un estudio global. Claves para su aplicación y desarrollo legislativo, Cátedra Garrigues-Thomson-Aranzadi, Cizur Menor, 2007, pp. 37-45. 
En 1991, mediante la Resolución 46/91, la Asamblea General adoptó unos Principios en favor de las personas de edad, que constituye un verdadero decálogo en términos similares a los reconocidos para las personas con discapacidad. Se trata de principios relativos a la independencia, participación, cuidados, autorrealización y dignidad, que informan la acción de los Estados miembros sin que, a pesar de su redacción, puedan ser considerados como el reconocimiento de derechos.

Posteriormente, tras la celebración del Año Internacional de las Personas Mayores en 1999, se celebraría la Segunda Asamblea Mundial del Envejecimiento en Madrid en el 2002, en la que se adoptó el Plan de Acción Internacional de Madrid en la Segunda Asamblea Mundial sobre el Envejecimiento realizada en España. Este Plan prestó especial atención a la situación de los países en desarrollo y define como temas centrales la realización de todos los derechos humanos y libertades fundamentales de todas las personas de edad, y la garantía de los derechos económicos, sociales y culturales de las personas mayores, así como de sus derechos civiles y políticos, así como la eliminación de todas las formas de violencia y discriminación en contra de las personas de edad. La voluntad política de los Estados participantes se reflejó en la Declaración Política en la que se promueve la colaboración con todos los agentes políticos y sociales.

Estas estrategias relacionadas con la dependencia se han manifestado de forma regional, desde la que se han adaptado las medidas a las necesidades y características de cada zona a través de la Comisión Económica para Europa $(\mathrm{CEPE})^{11}$ y la Comisión Económica para América Latina y el Caribe $(\mathrm{CEPAL})^{12}$.

Otros organismos internacionales han promovido estudios e informes sobre la cuestión, como es el caso de la Organización Mundial de la Salud, que ha contribuido en el abordaje de la dependencia a través de una concepción amplia de la salud que abarca la satisfacción de las aspiraciones personales y la interacción con el entorno que surge de la Declaración de Ottawa de 1986 y que se concreta en la Clasificación Internacional del Funcionamiento, de la Discapacidad y de la Salud de 2001. También la Organización Internacional

${ }^{11}$ Dentro de la CEPE se organizó, entre otras, la Conferencia Ministerial sobre Envejecimiento para Europa en Berlín en 2002, que dio lugar a la Estrategia Regional de Implementación del Plan de Acción Internacional de Madrid sobre el Envejecimiento 2002.

12 En el seno de la CEPAL se organizó primera Conferencia Regional Intergubernamental sobre Envejecimiento llevada a cabo entre el 19 y 21 de noviembre de 2003, y ratificada en la resolución 604 del Trigésimo periodo de sesiones de la CEPAL. En el año 2007, la CEPAL organizó la segunda Conferencia regional intergubernamental sobre el Envejecimiento en América Latina y el Caribe (Brasilia, Brasil, 4 al 6 de diciembre de 2007), donde los países miembros adoptaron la Declaración de Brasilia. 
del Trabajo (Una sociedad inclusiva para una población que envejece: el desafío del empleo y la protección social) o la Asociación Internacional de la Seguridad Social (Envejecimiento y vida productiva: protección social y sostenibilidad). Otras organizaciones han contribuido al debate en torno a la atención a la dependencia como el Foro de Valencia celebrado en 2002, Grupos de Expertos sobre la mejora de la calidad de vida de las personas mayores dependientes.

Como se puede apreciar, la aprobación de la LPAP se encuentra condicionada por las iniciativas desarrolladas a nivel internacional, que sirven de punto de referencia para su configuración, pero que no constituyen una exigencia para su aprobación ni imponen un contenido determinado.

\subsection{La atención a la dependencia en el marco del Consejo de Europa}

El Consejo de Europa tiene como objetivo desde su creación en 1949 favorecer en Europa un espacio democrático y jurídico común, organizado alrededor del Convenio Europeo de los Derechos Humanos y de otros textos de referencia sobre la protección del individuo.

En tanto entre sus objetivos se encuentra la protección de los derechos humanos y buscar soluciones comunes a los problemas a los que se enfrenta la sociedad, se sitúan como un ámbito adecuado para la promoción de políticas relacionadas con la dependencia a nivel regional que, además, influyen directamente en el desarrollo de las políticas comunitarias en el seno de la Unión Europea ${ }^{13}$.

La Carta Social Europea, suscrita en 1961 y sometida a sucesivas revisiones y alteraciones, constituye el marco esencial de la acción del Consejo de Europa en el ámbito de la dependencia. En su articulo 15 se refiere a la discapacidad y en su evolución se puede apreciar el paso de un modelo basado en la formación, rehabilitación y readaptación de las personas con discapacidad al reconocimiento del derecho de las personas con discapacidad a la autonomía personal, la integración social y la participación en la vida de la comunidad ${ }^{14}$.

${ }_{13}$ Entre sus objetivos, conforme al mandato político definido en la tercera Cumbre de los Jefes de Estado y de Gobierno (Varsovia, mayo de 2005), figuran el defender los derechos humanos, la democracia pluralista y la preeminencia del derecho; favorecer la toma de conciencia y el desarrollo de la identidad cultural de Europa así como de su diversidad; buscar soluciones comunes a los problemas a los que se enfrenta la sociedad, tales como la discriminación de las minorías, la xenofobia, la intolerancia, la bioética y la clonación, el terrorismo, la trata de seres humanos, la delincuencia organizada y la corrupción, la ciber criminalidad, y la violencia hacia los niños; desarrollar la estabilidad democrática en Europa acompañando las reformas políticas, legislativas y constitucionales.

${ }^{14}$ Así llama la atención sobre dicho cambio Cardona, J., "La protección de los derechos de los discapacitados en Europa”, en Mariño, F. y Fernández Liesa, C., La protección de las personas y grupos vulnerables, op. cit. p. 352. 
$\mathrm{Al}$ igual que sucedió en el caso de la ONU, la atención a la dependencia en el ámbito del Consejo de Europa no tuvo lugar desde un primer momento, sino que inicialmente se desarrollaron medidas dirigidas a las personas con discapacidad y a las personas mayores, respectivamente ${ }^{15}$.

En concreto fue esta segunda cuestión la que más motivó las actuaciones en el seno del Consejo de Europa, por considerarse un problema prioritario en atención a las características demográficas del territorio. La primera de las iniciativas fue la Resolución (1970) núm. 16, sobre política social y médicosocial en la vejez, a la que siguió la Resolución (1974) núm. 31, sobre asistencia sanitaria y social para las personas de edad avanzada que viven en su domicilio, que apuntan medidas para la integración de las personas mayores procurando mantenerlas en su entorno.

Esta medidas se complementaron con iniciativas posteriores dirigidas tanto a evitar el envejecimiento de la población (a través de políticas de natalidad como la contenida en la Recomendación de la Asamblea Parlamentaria (1986) núm. 1035, sobre las sociedades que envejecen en Europa y sus consecuencias económicas y sociales), como a atender las necesidades de las personas mayores, (Recomendación N R (87) 22 del Comité de Ministros sobre la detección y atención de las personas mayores).

A partir de la década de los noventa, las medidas relativas a personas dependientes se extendió a las personas discapacitadas con la Recomendación N R (90) 22 del Comité de Ministros sobre la protección de la salud mental de ciertos grupos vulnerables de la sociedad y la Recomendación N R (92) 6 del Comité de Ministros relativa a una política coherente para las personas minusválidas.

Junto a las medidas dirigidas a las personas mayores y discapacitados, se adoptaron otras iniciativas que manifiestan la formación de una verdadera política relativa a la dependencia al dirigirse a las personas a cargo de dependientes: Recomendación N. ${ }^{\circ} 2$ (1991) del Comité de Ministros de Estados Miembros del Consejo de Europa, relativa a la Seguridad Social de los trabajadores sin estatuto profesional, en la que se contienen medidas para el reconocimiento y protección de los que trabajan para personas dependientes.

La política del Consejo de Europa sobre la dependencia como tal termina por confirmarse en la Recomendación N. ${ }^{\circ}$ (98) 9 del Comité de Ministros, adoptada el 18 de septiembre de 1998, relativa a la dependencia. Se identifica y define la cuestión - convirtiéndose en un referente para todos los textos legales y doctrinales en la delimitación de la cuestión- señalando que se trata de un nuevo riesgo social que requiere atención pública y, se

${ }^{15}$ En este punto seguimos la exposición de Baviera Puig, I., La protección de la dependencia: un estudio global. op. cit., pp. 49-57. 
señala la necesidad de llevar a cabo una aproximación global y multidisciplinar de la atención de la dependencia y una acción común a nivel europeo. En concreto, recomienda a los Gobiernos de los Estados miembros velar por la sensibilización de la opinión pública en relación a la dependencia tal como es presentada en esta recomendación; orientar las medidas políticas en este campo de acuerdo a los principios que en ella se enuncian; asegurar que su legislación tenga en cuenta los principios generales y medidas de la recomendación o adoptar disposiciones conformes a estas reglas cuando introduzcan una nueva legislación.

A ésta siguieron otras en las que se atiende a otros colectivos como son los enfermos crónicos — Recomendación (1998) núm. 11, sobre la atención sanitaria a los enfermos crónicos-, así como a cuestiones concretas de estos colectivos - Recomendación (1999) núm. 4 sobre principios referentes a la protección jurídica de los mayores incapacitados-.

El tratamiento de la dependencia ha sido desde entonces una cuestión recurrente en el ámbito del Consejo de Europa que ha dedicado su atención a la mejora y armonización de los sistemas públicos a través de estudios como el Informe del Grupo de Expertos en la mejora de la calidad de vida de las personas dependientes, elaborado en 2002, en el que se comparan las distintas soluciones posibles para abordar la cuestión de la dependencia y se aportan directrices para el papel del Estado.

La dependencia pasa a ocupar así un papel central entre las prioridades que deben abordarse en el plano social dentro del Consejo de Europa, que exige el replanteamiento de la política de protección en su totalidad y, en concreto, de los sistemas de Seguridad Social. Así se aprecia en la Revisión de la Estrategia: Recomendación (2003) núm. 1591, nuevos desafíos de la política social; Recomendación (2004) núm. 1661, el nuevo contexto de la Seguridad Social en Europa.

\subsection{Valoración del marco internacional y comparado en su relación con la política sobre la dependencia en España}

Como se ha podido apreciar, ninguna de las iniciativas impulsadas desde instancias internacionales relevantes a efectos de la protección de la dependencia han obligado a la adopción de políticas concretas.

Los compromisos de los Estados y en concreto de nuestro país frente a la ONU y frente al Consejo de Europa se limitan a otros aspectos, ya que los tratados internacionales suscritos en uno y otro ámbito, de los que se derivan obligaciones concretas, se han centrado en el reconocimiento y la defensa de los derechos fundamentales individuales. 
En el desarrollo de las acciones a nivel internacional que se encuentran relacionadas con el ámbito social se reconoce y respeta escrupulosamente la soberanía de los Estados a la hora de configurar sus respectivos sistemas públicos de protección social. Todo lo más se disponen principios, directrices, recomendaciones para que los Estados tengan en cuenta problemas de carácter global y los afronten a partir de unos criterios comunes que pueden adaptar en función de sus propias características y preferencias.

Resultaría de todo punto contranatural para las características de las relaciones internacionales de cooperación y, por lo tanto, sería inaceptable desde un punto de vista jurídico, que se impusiera a los Estados un determinado modelo de atención. Además, en la hipótesis de que pudiera resultar factible desde un punto de vista político-jurídico, sería igualmente imposible formular un modelo concreto de protección de la dependencia que sirviese indistintamente para todos los Estados

De hecho, la situación de cada uno de los Estados en lo que se refiere a la política de atención a la dependencia es absolutamente dispar. Cada Estado dispone su propias soluciones atendiendo a sus características (población, desarrollo económico), sus propias tradiciones en el ámbito de la política social y sus preferencias. De este modo cada Estado cuenta con un modelo propio, específico y singular, sin perjuicio de que por razón de sus elementos básicos se puedan agrupar en modelos típicos.

En efecto, la asimetría en el tratamiento de la dependencia se puso de manifiesto realizados en el proceso de maduración de la política de la dependencia en España en diversos estudios ${ }^{16}$ y, posteriormente, en el Libro Blanco de la Dependencia, en cuyo Capítulo XI se agrupan los sistemas en tres grupos diferenciados que se corresponden con los modelos de Estado de Bienestar:

a) De protección universal (modelo Beveridge) para todos los ciudadanos y financiación mediante impuestos (países nórdicos y Holanda);

16 Sancho Castiello, M. T. (coord.), Vejez y protección social a la dependencia en Europa: iniciativas, recomendaciones del Consejo de Europa, Ministerio de Trabajo y Asuntos Sociales, Instituto de Migraciones y Servicios Sociales, IMSERSO, Madrid, 2001. También pueden encontrarse estudios comparados en Pérez Menayo, V., "Prestaciones de dependencia: situación comparada en la Unión Europea”, Revista del Ministerio de Trabajo y Asuntos Sociales, núm. 47, 2003, pp. 296 a 324; y, asimismo, Baviera Puig, I. op cit. pp. 85 a 138.

Se pueden encontrar estudios más recientes en De la Fuente Lavín, M., "Modelos de protección de la dependencia en la Unión Europea y factores de convergencia", Trabajo: Revista andaluza de relaciones laborales, núm. 18, 2006, pp. 17-37; Quintero Lima, M. G., "Modelos comparados en Europa de protección de las situaciones de dependencia", Temas laborales: Revista andaluza de trabajo y bienestar social, núm. 89, 2007, pp. 91-124; Avio, A., "Modelos comparados en Europa de protección de las situaciones de dependencia: el caso de Italia", Temas laborales: Revista andaluza de trabajo y bienestar social, núm. 90, 2007, pp. 11-26. 
b) De protección a través del Sistema de Seguridad Social (modelo bismarckiano), mediante prestaciones económicas y de servicios que se financian fundamentalmente con cotizaciones, aunque también con financiación presupuestaria de las prestaciones no contributivas y de la propia estructura del sistema (países de Centroeuropa);

c) De protección asistencial (ayuda social), dirigido a los ciudadanos carentes de recursos y financiado con impuestos (países del sur de Europa, excepto Francia que goza de un sistema de protección universal).

\section{La incidencia de la Convención de los Derechos}

DE LAS PERSONAS CON DISCAPACIDAD EN EL DESARROLLO Y APLICACIÓN DE LA LEY 39/2006, DE PROMOCIÓN DE LA AUTONOMÍA Y ATENCIÓN A LAS PERSONAS EN SITUACIÓN DE DEPENDENCIA

\subsection{El significado de la Convención y su conexión con el contenido de la LEPA}

A nivel internacional la cuestión de la autonomía personal y la atención a la dependencia ha sido objeto de iniciativas por parte de distintas organizaciones internacionales desde una perspectiva estrictamente programática hasta la aprobación en el ámbito de la ONU de la Convención sobre derechos de las personas con discapacidad.

Comos se ha podido comprobar desde las instancias internacionales, la intervención en materia de dependencia se ha caracterizado esencialmente por el respeto de las competencias estatales y su tratamiento fragmentado a partir de las medidas relacionadas con el envejecimiento de la población y con las personas con discapacidad.

Ha sido precisamente en este segundo ámbito en el que se han perfilado actuaciones con mandatos más concretos para los Estados miembros que, sin embargo, no llegaron a concretar obligaciones específicas. Así, las Normas Uniformes sobre la igualdad de oportunidades para las personas con discapacidad en 1993 sirven de legislación modelo para algunos países en cuanto normas básicas destinadas a dar a las personas con discapacidad las mismas oportunidades que a cualquiera. No obstante, no son un instrumento jurídicamente vinculante, por lo que no se puede exigir a los Estados el cumplimiento de su contenido.

Por otra parte, los instrumentos internacionales relacionados con los derechos fundamentales, como son la Declaración Universal de Derechos $\mathrm{Hu}-$ manos adoptada por la Asamblea General de la ONU en 1948 y el Conve- 
nio Europeo para la Protección de los Derechos Humanos de 1950 adoptada en el seno del Consejo de Europa, se proyectan desde una perspectiva formal reconociendo aquellos derechos directamente vinculados con la dignidad humana, pero sin atender a las condiciones (físicas, económicas) en que se encuentran los individuo para poder alcanzar el disfrute de dichos derechos.

A este respecto, la Convención sobre los Derechos de las Personas con Discapacidad supone un punto de inflexión porque plantea el tratamiento de la discapacidad (y, por tanto, de la dependencia) como una cuestión de Derechos humanos con carácter vinculante a nivel global ${ }^{17}$. En efecto, se trata de una Convención que introduce un "cambio paradigmático" de las actitudes y enfoques respecto de las personas con discapacidad, ya que se trata de un instrumento de derechos humanos con una dimensión explícita de desarrollo social que reconoce que las barreras y los prejuicios de la sociedad constituyen en sí mismos una discapacidad.

La Convención y su Protocolo Facultativo fueron aprobados el 13 de diciembre de 2006 y ha sido ratificada por nuestro país mediante Instrumento de 23 de noviembre de 2007. Se trata de un tratado internacional en el que se recogen los derechos de las personas con discapacidad así como las obligaciones de los Estados de promover, proteger y asegurar esos derechos. En ella se establecen también dos mecanismos de aplicación: el Comité sobre los Derechos de las Personas con Discapacidad, encargado de supervisar la aplicación de la Convención y la Conferencia de los Estados Partes, encargada de examinar cuestiones relacionadas con la aplicación de la Convención. Por lo tanto, se trata de un instrumento jurídicamente vinculante que obliga a nuestro país a cumplir con su contenido en los términos previstos en la misma.

En ella se adopta una amplia clasificación de las personas con discapacidad y se reafirma que todas las personas con todos los tipos de discapacidad deben poder gozar de todos los derechos humanos y libertades fundamentales. La discapacidad, si bien no se define de forma expresa ${ }^{18}$, se concibe como un concepto que evoluciona y que resulta de las barreras debidas a la

${ }_{17}$ Sobre la naturaleza de la Convención vid. Palacios, A. y Bariffi, F., La discapacidad como una cuestión de derechos humanos. Una aproximación a la Convención Internacional sobre los Derechos de las Personas con Discapacidad, Cinca, Madrid, 2007. Y de la misma autora Modelo social de discapacidad: orígenes, caracterización y plasmación en la Convención Internacional, Cinca, Madrid, 2008.

${ }^{18}$ La Convención no define explícitamente el vocablo "discapacidad"; es más, en el Preámbulo a la Convención se reconoce que "discapacidad" es un concepto que evoluciona (apartado e). Tampoco define la Convención la expresión "personas con discapacidad". No obstante, el tratado sí afirma que esa expresión incluye a las personas con deficiencias físicas, mentales, inte- 
actitud y al entorno que impiden la participación de las personas con discapacidad en la sociedad. Además, no se considera la discapacidad como una condición médica, sino más bien como el resultado de la interacción entre actitudes negativas o de un entorno que no es propicio y no se ajusta a la condición de las personas en particular; al existir las barreras esas personas no pueden participar como miembros activos de la sociedad y gozar plenamente de todos sus derechos. Por último, no se restringe su cobertura a personas concretas sino que, más bien, identifica personas con discapacidad física, mental, intelectual o sensorial a largo plazo a las que se les aplica la Convención. Al utilizar el término "incluyen" se asegura que no se restringe la aplicación de la Convención, y los Estados Partes también pueden asegurar la protección de otras personas, como las personas con discapacidad a corto plazo o que se consideren parte de dichos grupos.

Por lo expuesto puede afirmarse que la Convención abarca en todo caso las personas dependientes a las que se refiere la LEPA, ya que su objeto resulta más restringido en tanto se trata de las personas con dependientes (art. 1 LEPA), que se refiere a quienes precisan la atención de personas o ayudas importantes para realizar actividades básicas de la vida diaria o, en el caso de las personas con discapacidad intelectual o enfermedad mental, de otros apoyos para su autonomía personal (art. 2.2. LEPA). Este colectivo encaja perfectamente en el objeto de la Convención, independientemente de que la situación de dependencia (que se proyecta como una discapacidad a efectos de la Convención) se deba a enfermedad, accidente o envejecimiento.

El propósito de la convención es promover, proteger y garantizar el disfrute pleno y por igual del conjunto los derechos humanos por las personas con discapacidad. Para lo cual reconoce los siguientes principios generales: el respeto de la dignidad inherente, la autonomía individual, incluida la libertad de tomar las propias decisiones, y la independencia de las personas; la no discriminación; la participación e inclusión plenas y efectivas en la sociedad; el respeto por la diferencia y la aceptación de las personas con discapacidad como parte de la diversidad y la condición humanas; la igualdad de oportunidades; la accesibilidad; la igualdad entre el hombre y la mujer; el respeto a la evolución de las facultades de los niños y las niñas con discapacidad y de su derecho a preservar su identidad.

Los derechos explícitos que se indican en la Convención son la igualdad ante la ley sin discriminación; el derecho a la vida, la libertad y la seguridad de la persona; un igual reconocimiento como persona ante la ley e igual

lectuales o sensoriales a largo plazo que, ante diversas actitudes negativas u obstáculos físicos, pueden verse privadas de participar plenamente en la sociedad (artículo 1). 
capacidad jurídica; la protección contra la tortura; la protección contra la explotación, la violencia y el abuso; el derecho a que se respete la integridad física y mental; la libertad de desplazamiento y nacionalidad; el derecho a vivir en la comunidad; la libertad de expresión y de opinión; el respeto de la privacidad; el respeto del hogar y la familia; el derecho a la educación; el derecho a gozar de salud; el derecho al trabajo; el derecho a un nivel de vida adecuado; el derecho a participar en la vida política y pública; el derecho a participar en la vida cultural.

Como se puede comprobar, la Convención cubre una serie de ámbitos fundamentales tales como la accesibilidad, la libertad de movimiento, la salud, la educación, el empleo, la habilitación y rehabilitación, la participación en la vida política, y la igualdad y la no discriminación. En verdad, la Convención no crea nuevos derechos sino que se encarga de que los ya existentes puedan ser disfrutados por las personas con discapacidad. Nos centraremos a continuación en aquellos artículos de la Convención que resultan más relevantes en tanto su satisfacción tiene lugar en nuestro país a través del desarrollo de la LPAP.

\subsection{El contenido de la Convención relativo a la autonomía e independencia individual}

La Convención sobre Derechos de las Personas con Discapacidad reconoce en su Preámbulo la importancia que para las personas con discapacidad reviste su autonomía e independencia individual, incluida la libertad en la toma de sus propias decisiones (apartado n). La consecución de dicha autonomía e independencia exige atender a la diversidad de las situaciones en las que se encuentran las personas con discapacidad (apartado i), en particular a las que necesitan un apoyo más intenso (apartado j).

No sólo en el Preámbulo sino también entre los principios generales figura en primer lugar la autonomía individual, incluida la libertad de tomar las propias decisiones, y la independencia de las personas (art. 3 a). A estos principios se une asimismo el de participación e inclusión plenas y efectivas en la sociedad (art. 3 c), y la igualdad de oportunidades (art. 3 e).

Estos principios se concretan en el derecho a vivir de forma independiente y a ser incluido en la comunidad que recoge el artículo 19 de la Convención. En éste los Estados se comprometen a reconocer el derecho en igualdad de condiciones de todas las personas con discapacidad a vivir en la comunidad, con opciones iguales a las de las demás, y se comprometen a adoptar medidas efectivas y pertinentes, para facilitar el pleno goce de este derecho. 
Entre dichas medidas destacan aquellas que han adoptar los Estados miembros para asegurar que las personas con discapacidad tengan acceso a una variedad de servicios de asistencia domiciliaria, residencial y otros servicios de apoyo de la comunidad, incluida la asistencia personal que sea necesaria para facilitar su existencia y su inclusión en la comunidad y para evitar su aislamiento o separación de ésta (art. 19 b Convención). Asimismo, se incluye la obligación de garantizar que las instalaciones y los servicios comunitarios para la población en general estén a disposición, en igualdad de condiciones, de las personas con discapacidad y tengan en cuenta sus necesidades (art. 19 c) Convención).

El derecho a vivir de forma independiente necesita, para realizarse de forma efectiva, de la garantía de la movilidad personal a la que se refiere el artículo 20 de la Convención, que exige a los Estados adoptar medidas efectivas para asegurar que las personas con discapacidad gocen de movilidad personal con la mayor independencia posible.

La garantía se refiere a la movilidad personal lo que supone, por una parte, facilitar soluciones adaptadas a cada persona y, asimismo, el acceso a los medios que la hagan efectiva.

Debe tenerse en cuenta que la garantía de los Estados a la movilidad personal de las personas con discapacidad requiere el cumplimiento previo de la accesibilidad del entorno, las instalaciones y los servicios, conforme a lo dispuesto en el artículo 9 de la Convención que se analiza en el apartado anterior.

Además, y al igual que ocurre con la accesibilidad, la realización del derecho a la vida independiente en su dimensión de una mayor movilidad puede verse modulado por otros derechos y obligaciones reconocidas en la Convención, al constituir un elemento imprescindible para garantizar el derecho trabajo, a la salud, a la participación en procesos electorales; acceso a la justicia, al ocio, cultura y deporte, etc. Por lo cual puede generar obligaciones específicas adicionales que deberán considerarse a la luz de los correspondientes artículos de la Convención dentro de los ámbitos en que se analicen en este trabajo.

\subsection{Objetivo y alcance de las obligaciones de la Convención con respecto a la promoción de la autonomía y la atención a la dependencia}

El objetivo del artículo 19 de la Convención consiste en garantizar a la personas con discapacidad una vida de forma independiente y en comunidad con iguales opciones que las demás, y con plena inclusión y participación. 
De este modo el artículo 19 exige una garantía de autodeterminación personal, esto es, que las personas con discapacidad puedan decidir el cómo, dónde y con quién vivir, como cualquier otra persona. Con este objetivo, y teniendo en cuenta su vinculación a elementos externos para posibilitar su existencia en condiciones de igualdad, se dispone que deben tener la posibilidad de elegir entre distintos soluciones asistenciales (residencias, servicios, asistencia personal), de modo que puedan elegir la que consideren más conveniente para desarrollar su vida en sociedad.

Asimismo las instalaciones y servicios comunitarios deben estar a su disposición en igualdad de condiciones que a los demás. Esta puesta a disposición no se refiere a la accesibilidad de unas y otros — que se da por supuesto conforme al artículo 9-, sino que se trata de la posibilidad de acceder a la variedad de instalaciones y servicios existentes y deberán poder hacerlo en igualdad de condiciones que el resto.

Una concreción de este objetivo es el que figura en el artículo 20 que pretende asegurar que las personas con discapacidad gocen de movilidad personal con la mayor independencia posible.

Esta movilidad garantizada por los Estados parte debe partir del principio de la "autodeterminación dinámica", esto es, que cómo y cuándo quieren moverse y puedan hacerlo a costo asequible.

Asimismo debe garantizarse el acceso a las medidas necesarias para equiparar las funcionalidades motoras de las personas con discapacidad con respecto a las del resto. Esto supondría incluir tanto a personas con discapacidad física, como aquéllas con discapacidades sensoriales y mentales que afecten a la movilidad.

Debe distinguirse lo dispuesto en este artículo 20 con respecto a la movilidad de las obligaciones relativas al transporte, ya que éste último quedaría esencialmente sometido a lo dispuesto en el artículo 9 relativo a la accesibilidad. La movilidad se refiere a la traslación personal en un ámbito más básico que es el del normal desenvolvimiento al que no habilitan determinadas disfunciones físicas y mentales. Aunque la garantía de la movilidad puede alcanzar a los servicios de transporte cuando las medidas de accesibilidad no son suficiente y se hace necesario servicios especiales al no servir los disponibles al público en condiciones de accesibilidad.

La dimensión material de los artículos 19 y 20 de la Convención alcanza a una gran variedad de ámbitos ya que se refieren a todo aquello que resulte necesario para garantizar la vida independiente y la movilidad, lo que incluye servicios, bienes (tecnologías, dispositivos o ayudas técnicas) e instalaciones. En concreto, el artículo 19 c) se refiere a servicios de asistencia domiciliaria, residencial y otros servicios de apoyo, incluida la asistencia personal (apartado b), mientras que el artículo 20 b) menciona las formas 
de asistencia humana o animal e intermediarios, tecnologías de apoyo, dispositivos técnicos y ayudas para la movilidad.

A partir de todas estas medidas disponibles, debe tenerse en cuenta que la Convención no prevé un modelo concreto para garantizar el derecho a la vida independiente ya que, por una parte, el artículo 19 reconoce de forma genérica el derecho de todas las personas con discapacidad a vivir en la comunidad con opciones iguales, y determina que los Estados deberán adoptar medidas efectivas y pertinentes para facilitar el pleno goce de estos derechos. Más allá de esta previsión genérica las medidas a adoptar por los Estados deben respetar en todo caso la libertad de decisión de las personas con discapacidad en cuanto a la organización de su propia vida (esto es, el lugar, la compañía y el modo de vida), por lo que deben poder contar con la posibilidad de acceder a las distintas soluciones que sean necesarias para facilitar su existencia y su inclusión en la comunidad y para evitar su aislamiento, sin que se manifieste una preferencia por ninguna de ellas que pueda derivar en una imposición. Se menciona la posibilidad de optar por residencias, servicios domiciliarios, y cualesquiera otros servicios asistenciales, incluida la asistencia personal.

Otro tanto ocurre con la movilidad personal, ya que el artículo 20 parte del reconocimiento del derecho a las personas con discapacidad de decidir el modo y momento en la movilidad personal, para lo cual se debe facilitar el acceso de las personas con discapacidad a formas de asistencia humana o animal e intermediarios, tecnologías de apoyo y dispositivos técnicos y ayudas.

Por otra parte, debe tenerse en cuenta que aunque se reconoce el derecho a la vida independiente no se hace con carácter prestacional, ya que el artículo 19 dispone de forma genérica que se adoptarán las medidas efectivas y pertinentes para facilitar el pleno goce de este derecho, y que se garantizará en especial el acceso a las soluciones que así lo hagan posible y las puesta a disposición de instalaciones y servicios comunitarios. Por lo tanto, si bien es una obligación de los Estados prever las medidas para garantizar este derecho a la vida independiente, no lo es proveerlas de forma directa ni indirecta. En efecto, los Estados deben asegurar la existencia de una oferta suficiente de las medidas que sean necesarias, lo cual no significa ni que tengan que prestarlas directamente ni que tenga que asumir el coste de las mismas.

Exactamente igual ocurre con la movilidad, que, si bien no se reconoce como derecho, se garantiza a través de la disposición de la obligación de los Estados de disponer las medidas efectivas que sean necesarias para asegurarla. En este caso, se aprecia mejor la ausencia de una obligación de provisión pública de los medios necesarios para garantizar la movilidad por parte de 
los Estados, ya que el artículo 20 dispone que deben adoptar medidas efectivas para asegurar que gocen de movilidad personal, "facilitándola en la forma y en el momento que deseen a un costo asequible", y "facilitando el acceso" a aquellos medios necesarios para "una movilidad de calidad, incluso poniéndolos a su disposición a un costo asequible.

El facilitar la movilidad y el acceso a las medidas necesarias para ello no implica necesariamente la asunción total del coste económico, con respecto al cual únicamente deben garantizar que sea asequible. La asequibilidad en los medios que garantizan la movilidad puede garantizarse a través de diversas medidas que incluyen la prestación pública directa con carácter gratuito, a la prestación indirecta con asunción de su coste (total o parcial), subvenciones, ayudas (que pueden ser directas o indirecta y totales o parciales).

En la medida que los Estados asuman la prestación de las medidas necesarias para garantizar la vida independiente y la movilidad, deberá tenerse en cuenta el artículo 4.2 de la Convención, que si bien se refiere literalmente a los derechos económicos, sociales y culturales, no cabe duda que en una interpretación sistemática y teleológica hace referencia a los derechos prestacionales, con respecto a los que dispone que los Estados Partes deberá adoptar medidas hasta el máximo de sus recursos disponibles y, cuando sea necesario, en el marco de la cooperación internacional, para lograr, de manera progresiva, el pleno ejercicio de estos derechos.

Por último debe tenerse en cuenta que las medidas relativas a la vida independiente y a la movilidad personal se enmarcan, cuando se prestan por los poderes públicos, en los servicios sociales. Sin embargo, desde de la perspectiva de la Convención, deben distinguirse aquéllos vinculados con la vida independiente y la movilidad personal a los que se refieren los artículo 19 y 20, de aquellos otros servicios distintos de éstos dispuestos para la protección social de manera que se garantice un nivel de vida adecuado tanto para las personas discapacitadas como para sus familias, a las que se refiere el artículo 28 de la Convención y que se analiza en el ámbito 7 del presente estudio.

\subsection{Concreción de las obligaciones dispuestas por la Convención con respecto a la promoción a la autonomía y la atención a la dependencia}

El artículo 19 parte del reconocimiento por parte de los Estados del derecho de todas las personas con discapacidad a vivir en la comunidad, con opciones iguales a las de las demás, y gozar de este derecho con plena inclusión y participación en ella, para lo cual deben cumplir con las siguientes obligaciones: 
a) Obligación de carácter general: adoptar medidas efectivas y pertinentes para facilitar el pleno goce del derecho a la vida independiente por las personas con discapacidad y su plena inclusión y participación en la comunidad. Este derecho se garantiza esencialmente a través del cumplimiento de las obligaciones específicas que se detallan a continuación y que son el respecto a su autodeterminación en la organización de su propia vida, la posibilidad de elegir entre distintas soluciones asistenciales y la puesta a disposición de instalaciones y servicios comunitarios atendiendo a sus necesidades.

b) Obligaciones específicas:

a) Asegurar la libre determinación del lugar y condiciones de residencia. En tanto la necesidad de determinados servicios y atenciones por parte de las personas con discapacidad puede condicionar la autodeterminación en el desarrollo de su propia vida (estancias en residencias, etc.), debe garantizarse que no se verán obligadas a vivir con arreglo a un sistema de vida específico.

b) Asegurar el acceso a los servicios necesarios para facilitar su existencia y su inclusión en la comunidad y para evitar su aislamiento o separación de ésta. Se trata de servicios de asistencia domiciliaria, residencial y otros servicios de apoyo de la comunidad, incluida la asistencia personal.

c) Asegurar que las instalaciones y los servicios comunitarios para la población en general estén a disposición, en igualdad de condiciones, de las personas con discapacidad y tengan en cuenta sus necesidades.

Por su parte, las obligaciones dispuestas en el artículo 20 se estructuran de la siguiente manera:

a) Obligación de carácter general: adoptar las "medidas efectivas" para asegurar la movilidad personal, lo cual implica una mayor vinculación de los poderes públicos con respecto al cumplimiento de esta obligación.

b) Obligaciones específicas para garantizar de forma directa la movilidad: entre las medidas efectivas para asegurar la mayor movilidad personal posible de las personas con discapacidad se señalan las siguientes:

a) Facilitar las condiciones para la movilidad personal: disponibilidad material, temporal y económica de las condiciones necesarias que garanticen dicha movilidad. 
b) Facilitar el acceso a los medios (incluso poniéndolos a disposición a un costo asequible) que garanticen una movilidad personal de calidad. Pueden ser formas de asistencia humana o animal e intermediarios, tecnologías de apoyo, dispositivos técnicos y ayudas.

c) Obligación de facilitar formación sobre movilidad tanto a las personas discapacitadas como al personal especializado que trabaje con ellas.

d) Obligación de fomentar que los fabricantes de ayudas, dispositivos y tecnologías relacionados con la movilidad tengan en cuenta todos los aspectos relacionados con la movilidad de las personas con discapacidad.

\subsection{Valoración del cumplimiento de las obligaciones relativas al derecho a la vida independiente}

A) Obligaciones relativas a la vida independiente y a la inclusión en la comunidad. En España se ha desarrollado un enorme esfuerzo institucional por garantizar el derecho de las personas con discapacidad a una vida independiente en el sentido que se exige en el artículo 19 de la Convención. Destaca la existencia de diversas líneas de actuación seguidas por todos los poderes públicos que tratan de garantizar el disfrute de este derecho con carácter pleno.

Por una parte, la acción de la Seguridad Social (tanto en su dimensión contributiva como no contributiva) protege a las personas con discapacidad facilitando esencialmente prestaciones dinerarias que permiten el mayor grado de independencia a la hora de organizar su propia vida.

Por otra, la intervención en materia de servicios sociales garantiza las condiciones de prestación de aquellos servicios que resultan necesarios para desarrollar una vida independiente (residenciales, domiciliarios, personales, etc.). A lo que se añade la cobertura pública del coste de estos servicios en función de los recursos, etc.

Por último, el sistema de protección social de las personas con discapacidad se ha completado con la aprobación de la LEPA, que reconoce como un derecho subjetivo de ciudadanía la promoción de la autonomía personal y la atención a las personas en situación de dependencia, para lo cual dispone las bases del Sistema para la Autonomía y la Atención de la Dependencia.

Por razón de las características de estos tres ámbitos de cobertura, es posible afirmar que España cumple con las obligaciones mínimas dispuestas 
en el artículo 19 de la Convención en tanto, en primer lugar, reconoce no sólo el derecho a la autonomía de las personas con discapacidad sino el derecho a las prestaciones necesarias para ello.

Se encuentra a disposición de las personas con discapacidad una variedad suficiente de servicios para facilitar su existencia y su inclusión en la comunidad, y en la medida que éstos son provistos por las Administraciones Públicas existe una flexibilidad suficiente para que no se vean abocadas a tener que vivir con un sistema de vida impuesto. Así, las prestaciones de la LEPA son suficientemente variadas (servicios y prestaciones económicas), y su adjudicación se hace de forma racional, proporcionada e individualizada de modo que se ajusta a las necesidades y condiciones de los destinatarios, con una preferencia por aquellas prestaciones que permiten un mayor grado de autonomía. En el caso de las prestaciones de la Seguridad Social, su naturaleza económica promueve la independencia en su desarrollo.

Por último, la acción del Estado, CC.AA. y entes locales garantizan la puesta a disposición de las instalaciones y servicios comunitarios a las personas con discapacidad, esencialmente por la condición de accesibilidad que se exige a los mismos.

B) Obligaciones relativas a la movilidad. Las medidas dirigidas a las personas con discapacidad dispuestas desde el Sistema para la Autonomía y Atención a la Dependencia, desde la Seguridad Social y desde los Servicios Sociales garantizan su movilidad personal, en las condiciones de disponibilidad (modal y temporal) y de asequibilidad a la que se refiere el artículo 20. Asimismo desde estas tres dimensiones se garantiza no sólo la posibilidad de acceder a las formas de asistencia, tecnologías, dispositivos y ayudas necesarias para su movilidad, sino su disfrute efectivo, no ya a un coste asequible sino con carácter (total o parcialmente) gratuito gracias a su cobertura pública. Por lo tanto, es posible afirmar que España cumple con las obligaciones dispuestas en el artículo 20 de la Convención.

No obstante, debe tenerse en cuenta que las limitaciones (materiales, funcionales, económicas, etc.) sobre las medidas que permiten a una persona con discapacidad una movilidad equivalente a cualquier otra y que garantiza su vida independiente no se ajustan a los principios de la Convención expresados en el artículo 3 (respeto a la autonomía individual e independencia, no discriminación, participación plena, igualdad de oportunidades). Esto no implica que cualquier limitación impuesta por parte de los Estados en estas medidas implique un incumplimiento del contenido de la Convención. En la Convención se establecen unas obligaciones mínimas que resultan de inexcusable cumplimiento para los Estados, por enci- 
ma de las cuáles los Estados tampoco pueden actuar libremente sino que dentro de este margen se encuentran obligados por los principios inspiradores de la propia Convención, a los que deberán de ajustarse en la mayor medida posible.

Por lo tanto, el cumplimiento con el mínimo de las obligaciones dispuestas en el artículo 20 de la Convención no quita que se deban realizar todas las mejoras posibles en las medidas adoptadas en nuestro país para garantizar la movilidad y procurar que se haga efectiva cada vez con mayor independencia y calidad. Por lo tanto se deben reconsiderar algunas cuestiones que, sin constituir un incumplimiento de la obligaciones específicas de la Convención, no se ajustan a su finalidad.

En primer lugar, debe tenerse presente que la posibilidad que se reconoce a los Estados de optar por subvencionar aquellas medidas que garanticen la movilidad no significa que no exista una preferencia por aquéllas que sean más adecuadas para la realización de los principios de igualdad, autonomía e independencia. Por lo tanto, en la medida que resulte posible, se deberá permitir que sean las propias personas con discapacidad las que opten, y, en caso de que no sea posible por razones organizativas, dar preferencia a aquéllas que faciliten una mayor libertad de decisión (prestaciones económicas frente a servicios residenciales).

En segundo lugar, existen limitaciones en la aplicación de las medidas garantizadoras de la movilidad. El artículo 19 de la LPAP limita la prestación económica de asistencia personal a la educación y al trabajo. Al margen de la afectación del derecho a la cultura, ocio y deporte reconocido en el artículo 30 de la Convención, este tipo de limitaciones deben erradicarse para no condicionar los ámbito de movilidad de la vida de las personas discapacitadas, ni afectar a su autonomía e independencia, que deben disfrutar en igualdad de condiciones que cualquier otro.

Por último, en cuanto a la cuestión del copago, debe partirse de que la Convención no impone a los Estados la cobertura pública de las medidas dirigidas a garantizar la movilidad, y deja margen al respecto a partir de un mínimo que es la garantía de acceso a coste asequible. No obstante los principios de la Convención apunta a que los Estados, dentro de dicho margen, garanticen la igualdad y procuren la realización del mayor grado de independencia posible de las personas con discapacidad. Por esta razón debería replantearse la cuestión del copago que afecta tanto a la igualdad como a la independencia, que se hace depender del nivel económico de la persona con discapacidad, y que por lo tanto no se ajusta a los principios que inspiran la Convención. 
C) Formación e investigación en materia de movilidad. La capacitación profesional en habilidades relacionadas con la movilidad se encuentra en incluida en los diversos estudios relacionados con la discapacidad. La oferta formativa en nuestro país en materia de discapacidad parece suficiente.

La formación en este ámbito se ha visto recientemente reforzada al establecerse una serie de exigencias en cuanto a la formación de las personas que prestan sus servicios en el Sistema para la Autonomía y de Atención a la Dependencia, con la intención de profesionalizar su actividad de forma que sea de la mayor calidad. Así se dispone en el artículo 36 LEPA dentro del Capítulo dedicado a la calidad en los servicios asistenciales. En aplicación de éste el Acuerdo de 28 de noviembre de 2008 adoptado en el seno del Consejo Territorial de la Dependencia sobre criterios comunes de acreditación para garantizar la calidad de los centros y servicios del SAAD, ha establecido un programa de cualificación profesional para aquellos que trabajan con dependientes.

La capacitación en habilidades relacionadas con la movilidad a las personas con discapacidad aparece recogida esencialmente en la normativa autonómica sobre servicios sociales

A través de todas estas previsiones y actuaciones se cumple con lo exigido en el artículo 20.2 c) de la Convención. No obstante, al hacer referencia a la formación de las personas con discapacidad y de los profesionales que trabajan con éstas de forma genérica, convendría hacer un seguimiento de la concreción que se haga de la cuestión específica de la movilidad.

En cuanto al fomento de la adecuada fabricación de dispositivos y ayudas técnicas relacionados con la movilidad, el artículo 20 d) de la Convención exige únicamente que se aliente a que en la fabricación de ayudas y dispositivos para la movilidad y de apoyo se tengan en cuenta todos los aspectos relacionados con la movilidad.

Y por otra parte, esta obligación resulta ampliamente cumplida en España ya que, por una parte existe una conexión entre las obligaciones derivadas de la accesibilidad y del diseño para todos con la fabricación de ayudas y dispositivos para la movilidad y por otra, se ha desarrollado una amplia política pública de investigación en materia de ayudas para la movilidad, y dispositivos y tecnologías de apoyo, que tiene incidencia directa en la actividad privada de los fabricantes. A través de los diversos planes y desde los centros públicos y privados creados a tal efecto se consigue avanzar en la investigación de las tecnologías relacionadas con la movilidad. Los resultados recogen todos los aspectos de la movilidad de las personas con discapacidad y revierten en la actividad privada de los fabricantes. 


\section{EL SISTEMA PARA LA AUTONOMÍA Y ATENCIÓN A LA DEPENDENCIA EN EL DESARROLLO DEL PROCESO DE INTEGRACIÓN COMUNITARIA DE LA UNIÓN EUROPEA}

\section{La EVOLUCiÓN DE LAS MEDIDAS RELATIVAS A LA DEPENDENCIA EN EL PROCESO DE INTEGRACIÓN COMUNITARIO-EUROPEO DE LA UNIÓN EUROPEA}

En las Comunidades Europeas, al igual que en los ámbitos internacionales analizados, las primeras iniciativas relacionadas con la dependencia se encontraban relacionadas con el envejecimiento de la población ${ }^{19}$.

Estas medidas no aparecieron hasta la década de los años ochenta, no sólo porque hasta entonces no había existido una verdadera preocupación por dicho asunto sino, y sobre todo, porque las Comunidades Europeas no contaban por entonces con competencia alguna para intervenir, siquiera indirectamente, en aspectos relacionados con la política social - lo que no impedía la introducción de medidas relacionadas con este ámbito (como en el caso de las pensiones) de forma indirecta-.

Será con ocasión de la Primera Asamblea Mundial sobre el Envejecimiento de 1982, cuando el Parlamento Europeo adoptó una Resolución de 18 de febrero de 1982, sobre la situación y los problemas de las personas de edad avanzada en la Comunidad Europea, que es la primera de diversas iniciativas mediante las que se llama la atención sobre la cuestión ${ }^{20}$.

La preocupación coincidió con la superación del enfoque exclusivamente económico que había primado hasta entonces en el proceso de integración comunitario europeo, con la inclusión en los Tratados fundacionales mediante el Acta Única Europea de 1986, de un título específico dedicado a la cohesión económica y social, otro a la investigación y desarrollo tecnológico, y uno último al medio ambiente.

Las medidas concretas se retrasarían hasta que, en la década siguiente, se adoptaron a partir de la Comunicación de la Comisión sobre las personas de

19 Para un seguimiento exhaustivo del proceso histórico de formación de la política exclusivamente relacionada con las personas mayores vid. Fernández de GATTA, D. "La política relativa a la dependencia derivada del envejecimiento de la población en la Unión Europea”, en GARcía Trascasas, A. y Reguero Celada, J. (coords.), Cuestiones sobre la dependencia, Comares, Granada, 2007, pp. 1-55. Asimismo puede consultarse Baviera Puig, I., op. cit., pp. 62-84.

${ }^{20}$ De esta Resolución surgió la Recomendación 82/857/CEE del Consejo, de 10 de diciembre de 1982, sobre la flexibilización de la edad de jubilación. Posteriormente se aprobaron por el Parlamento Europeo la Resolución de 10 de marzo de 1986 en materia de ayudas a ancianos y la Resolución de 14 de mayo de 1986, sobre acción comunitaria para mejorar la situación de las personas de edad avanzada y declaración de un Año Europeo en la materia. 
edad avanzada (COM 199080 final), de 24 de abril. En concreto se trata de la Decisión 91/49/CE del Consejo, de 26 de noviembre de 1990, relativa a las acciones comunitarias en favor de las personas de edad avanzada. Esta iniciativa se respaldó con la celebración en 1993 del Año Europeo de las personas de edad avanzada y de la solidaridad entre generaciones (Decisión 92/440/CEE), que dio como resultado diversas acciones dirigidas específicamente a las personas mayores ${ }^{21}$.

Este proceso coincidió con un incremento de los fundamentos jurídicos para intervenir en la dimensión social a través de la Carta comunitaria de los derechos sociales fundamentales de los trabajadores de 1989 y, sobre todo, por la introducción de competencia específicas en materia social mediante el Tratado de la Unión Europea de 1992 que llevó a cabo una reformulación del proceso de integración comunitario y de la propia Comunidad Económica Europea, lo que se refleja significativamente en la pérdida de su apelativo de "Económica", por lo que pasa a denominarse Comunidad Europea (CE) con la consiguiente ampliación de sus fines y objetivos (arts. 2 y 3) más allá de lo estrictamente económico.

A partir de este momento y hasta la actualidad, aunque existe un fundamento específico para seguir interviniendo en cuestiones de protección social desde la Unión, se reconoce que las competencias en este ámbito son exclusivas de los Estados miembros, que son los únicos que pueden determinar el diseño y alcance de sus respectivos sistemas de protección social, sin perjuicio de las directrices contenidas en el Título XI del Tratado el respeto al resto de sus disposiciones relativas al mercado interior, la libre competencia, etc.

Sobre estas bases, a partir del cambio de siglo, comenzó a forjarse a nivel comunitario una verdadera política relacionada con la dependencia - o más bien con los cuidados de larga duración, como se identifican en los documentos comunitario- justificada por la necesidad de dar respuesta a los cambios demográficos en los Estados miembros que, junto a los cambios económicos, exigían una modernización de la política social ${ }^{22}$, lo que se

${ }^{21}$ Le seguirían otras iniciativas como la Recomendación del Consejo de 30 de junio de 1993, sobre regímenes flexibles de jubilación; la Decisión 93/512/CEE, del Consejo, de 21 de septiembre de 1993, relativa a la tecnología para las personas mayores y discapacitados; la Resolución del Parlamento Europeo, de 24 de febrero de 1994, sobre medidas a favor de personas de edad avanzada; y la Resolución del Consejo de 29 de junio de 1995, relativa a Empleo de los Trabajadores de Edad Avanzada.

${ }^{22}$ Estas dos cuestiones se reflejan en sendas Comunicaciones de la Comisión como son "Hacia una Europa para todas las edades. Fomentar la prosperidad y la solidaridad entre generaciones" COM (99) 221 final y "Una estrategia concertada para modernizar la protección social" COM (1999) 347 final. 
habría de desarrollar dentro de un proceso mucho más amplio de progreso económico y social marcado por la Estrategia de Lisboa de 2000.

En concreto, el tratamiento de la dependencia y de toda la Política Social en la Unión Europea se encuentra condicionada por la pretensión de la Estrategia de Lisboa de convertir (en 2010) a la economía europea en la más competitiva y dinámica del mundo, capaz de crecer económicamente de manera más sostenible con más y mejores empleo y con mayor cohesión social.

De acuerdo a las directrices de la Estrategia de Lisboa que pretende modernizar la protección social y promover la integración social se aprobó simultáneamente la Agenda de Política Social [Comunicación de la Comisión de 28 de junio de 2000 COM (2000) 379] que incluye entre sus objetivos, además del pleno empleo y la calidad en el trabajo, la calidad de la política social a través de su modernización; y, asimismo, la Comunicación "Evolución futura de la protección social desde una perspectiva a largo plazo: pensiones seguras y viables" [COM (2000) 622 final], que determina el desarrollo de la política en materia de Seguridad Social en cuanto sistema paralelo y complementario en el tratamiento de la dependencia.

El desarrollo de las políticas sociales en la Unión Europea en este marco se centra esencialmente en ámbitos como las pensiones o la inclusión social, apartando la cuestión de la dependencia únicamente a través de medidas dirigidas a abordar la cuestión del envejecimiento de la población y la atención a las personas mayores que motivaron sucesivas comunicaciones de la Comisión, en las que se manifiesta la preocupación por el futuro de los sistemas sanitarios y los cuidados de larga duración en aspectos concretos como su accesibilidad, calidad y sostenibilidad financiera y se llegan a apuntar algunas medidas legislativas necesarias a adoptar por los Estados miembros ${ }^{23}$.

En este momento, y como consecuencia de la ausencia de competencias directas sobre los sistemas de protección de los Estados miembros, se impulsó a nivel comunitario el método abierto de coordinación que se venía aplicando al ámbito de la inclusión social desde el 2000 y que, posteriormente, se extendería al ámbito de la sanidad y de la asistencia de

${ }^{23}$ Se trata de la Comunicación "La respuesta de Europa al envejecimiento a escala mundial. Promover el progreso económico y social en un mundo en proceso de envejecimiento" [COM (2000) 143 final]; la Comunicación sobre "El futuro de la asistencia sanitaria y de la atención a las personas mayores: garantizar la accesibilidad, la calidad y la sostenibilidad financiera" [COM (2001) 723 final] en las que se fijan los tres objetivos señalados; el Informe conjunto de la Comisión y del Consejo "Apoyar las estrategias nacionales para el futuro de la asistencia sanitaria y los cuidados a las personas mayores" [COM (2002) 774 final], en el que se proponen medidas legislativas concretas. 
larga duración, con el que se han conseguido grandes resultados a través del intercambio de buenas prácticas que han permitido apoyar los esfuerzos a nivel nacional ${ }^{24}$.

De forma paralela a todas estas iniciativas debe tenerse en cuenta la acción del Tribunal de Justicia de las Comunidades Europeas que, ha venido desarrollando una jurisprudencia proclive al reconocimiento y extensión de las prestaciones relacionadas con la dependencia ${ }^{25}$. Aunque se trata de una sucesión de sentencias sobre cuestiones concretas, debe tenerse en cuenta la singularidad de la jurisprudencia comunitaria en la construcción del proceso de integración.

La ausencia de una competencia comunitaria específica en el ámbito de la protección social pudo haberse solucionado con la ratificación y aprobación definitiva del Tratado por el que se constituye una Constitución para Europa firmado en 2004. Al margen del modelo social que sistematiza la sedicente Constitución Europea, en su articulado tiene lugar lo que se ha denominado como la consagración del deber de protección de la dependencia (arts. III 210.2 b) y II 94$)^{26}$, lo que hubiera supuesto el fundamento para el desarrollo de una eventual política comunitaria en este ámbito. Sin embargo, el abandono del proceso de aprobación mantuvo el status quo alcan-

${ }^{24}$ En esta ámbito pueden encontrarse la Comunicación de la Comisión "Refuerzo de la dimensión de la estrategia de Lisboa: racionalización del método abierto de coordinación en el ámbito de la protección social" [COM (2003) 312 final], asimismo la Comunicación "Modernizar la protección social para el desarrollo de una asistencia y una asistencia de larga duración de calidad, accesibles y duraderas: apoyos a las estrategias nacionales a través del método abierto de coordinación" [COM (2004) 304 final].

25 Una referencia a las sentencia más relevantes — como son, la de 5 de marzo de 1998 (C160/96), caso Molenaar; la sentencia de 8 de marzo de 2001 (C-215/99, asunto Jauch); sentencia de 21 de febrero de 2006 (C-286/03, asunto Hosse); sentencia de 8 de julio de 2004 (C502/01 y C-31/02, asunto Gaumain-Cerri y Brath) — puede encontrarse en Baviera Puig, I. op. cit. pp. 76-84.

${ }^{26}$ Sobre el modelo social en la Constitución Europea vid. Vida Fernández, J. El modelo social en la Constitución Europea: análisis presente y propuestas de futuro, Fundación Alternativas, Madrid, 2006. En el artículo III 210 del Tratado por el que se aprueba una Constitución para Europa se reconoce la seguridad social y la protección social de los trabajadores. Por otra parte, en el artículo II 94 se dispone que a Unión reconoce y respeta el derecho de acceso a las prestaciones de seguridad social y a los servicios sociales que garantizan una protección en casos como la maternidad, la enfermedad, los accidentes laborales, la dependencia o la vejez, así como en caso de pérdida de empleo, según las modalidades establecidas por el Derecho de la Unión y las legislaciones y prácticas nacionales. Sobre esta oportunidad perdida resulta muy recomendable la consulta del trabajo de De la Quadra-Salcedo Janini, T. y Suárez Corujo, B., "La garantía de los derechos sociales en la Constitución Europea. La consagración de la dependencia como contingencia protegida por los Sistema de Seguridad Social”, Revista del Ministerio de Trabajo y Asuntos Sociales, núm. 57, 2005, pp. 471-526. 
zado hasta entonces y que es precisamente el existente durante la elaboración y aprobación de la LEPA.

De forma paralela al fallido proceso de reforma de los Tratados fundacionales se llevó a cabo una revisión de la Estrategia de Lisboa a mitad del periodo previsto para su ejecución (2000-2010), con la que se reajustaron los objetivos inicialmente planteados y se intensificaron las medidas para alcanzar los definidos ${ }^{27}$. En línea con los planteamientos originales de la Estrategia de Lisboa, se mantiene el planteamiento de que el creamiento económico y el empleo son requisitos imprescindibles para la cohesión social y que ésta puede servir a aquéllos: pleno empleo, calidad y productividad laboral y cohesión social deben traducirse en prioridades claras y mensurables como atraer más personas al mercado laboral, aumentar las tases de empleo y la prolongación de la vida activa, reformar los sistemas de protección social, reflexionar sobre la financiación sostenible del sistema social, entre otras.

Este ambicioso proceso de reformas interrelacionadas se ha venido proyectado en el caso de la protección social, a través de la Comunicación sobre la Agenda Social [COM (2005) 33 final] en la que se establecen tres ejes de acción, como son aumentar la confianza de los ciudadanos, alcanzar el pleno empleo y conseguir una sociedad más solidaria, para lo que se plantea proyectar el método abierto de coordinación a la asistencia sanitaria y a los cuidados de larga duración.

Sin embargo, las medidas relativas a la Política Social no pueden considerarse de forma aislada sino que deben situarse dentro de una perspectiva más amplia poniéndolas en relación con las demás medidas de reforma propias de la Estrategia de Lisboa. A este respecto resultan significativos posteriores documentos de la Comisión en los que se insiste en estos planteamientos, como la Comunicación: "Los valores europeos en un mundo globalizado" [COM (2005) 525 final], en la que se afirma que los desafíos de la globalización para Europa sólo pueden afrontarse si se consolidan recíprocamente unos buenos resultados económicos y unos sistemas sociales eficaces, todo ello mediante nuevas actitudes de los ciudadanos frente al trabajo y la modernización de los servicios sociales ${ }^{28}$.

${ }^{27}$ Dichas revisión tiene como principales documentos la Comunicación del Presidente de la Comisión "Trabajando juntos por el crecimiento y el empleo Relanzamiento de la Estrategia de Lisboa” [COM (2005) 24 final], así como las Conclusiones de la Presidencia del Consejo Europeo de Bruselas de 22 y 23 de marzo de 2005 "Reactivar la Estrategia de Lisboa: una asociación para el crecimiento y el empleo" y del Consejo Europeo de Bruselas de 23 y 24 de marzo de 2006 "Aplicación de la Estrategia de Lisboa renovada para el crecimiento y el empleo".

28 Estos planteamientos se manifiestan de forma expresa en la Comunicación de la Comisión de 17 de octubre de 2007 titulada "Modernizar la protección social en aras de una mayor 
Asimismo, la Comunicación "Ha llegado la hora. La nueva asociación para el crecimiento y el empleo" [COM (2006) 30 final], insiste en la doble encrucijada que supone, que la globalización y el cambio demográfico exigen cambios estructurales poniendo el acento en la disminución de trabajadores y el aumento de los costes económicos por el envejecimiento poblacional, cuestión que ha motivado sucesivas Comunicaciones de la Comisión ${ }^{29}$. Dentro de la estrategia general, las iniciativas de la Comisión son cada vez más específicas y se proponen medidas que inciden en los planteamientos de los Estados miembros en ámbitos como la atención a la dependencia: así se propone, entre otras iniciativas, el aumento de los incentivos financieros para que los trabajadores de edad continúen en activo, la creación de vínculos entre el derecho a una pensión y la esperanza de vida restringiendo las jubilaciones anticipadas, la revisión de los regímenes de discapacidad y los sistemas de atención sanitaria y de larga duración.

Sin duda, la atención a la dependencia constituye un elemento de creciente importancia en el desarrollo de la Política Social, por lo que se le presta una especial atención, como se pone de manifiesto en los Informes conjuntos sobre protección social e inclusión social 2008 y 2009 [COM (2008) 42 final y COM (2009) 58 final]. En particular en el primero de ellos se advierte del aumento de las necesidades de cuidados de larga duración. Por lo demás se señalan los retos que asumen los sistemas nacionales que se comprometen con el acceso universal a cuidados de larga duración de gran calidad y al alcance de todos, si bien muchos países todavía no se ha logrado una fórmula de financiación viable, recomendando un equilibrio adecuado entre responsabilidades públicas y privadas y cuidados formales e informales, así como los cuidados en un marco residencial o comunitario que de cuidados institucionales, pero muchos Estados miembros siguen teniendo dificultados para ofrecer servicios de esa calidad. Asimismo, la mejo-

justicia social y una cohesión económica reforzada: promover la inclusión activa de las personas más alejadas del mercado laboral" [COM (2007) 620].

${ }^{29}$ En efecto, son numerosos en este período los documentos relativos envejecimiento de la población, como el Dictamen del Consejo Económico y Social Europeo sobre "Relaciones entre generaciones" de 28 de junio de 2005, el Libro Verde sobre los "Frentes a los cambios demográficos, una solidaridad entre generaciones", Comunicación COM (2005) 94 final, así como la Comunicación "El futuro demográfico de Europa: transformar un reto en una oportunidad" [COM (2006) 571 final]. A éstas se unen otras dirigidas a encajar los problemas derivados de una población envejecida y a facilitar su resolución como la Comunicación de la Comisión de 10 de mayo de 2007 titulada "Promover la solidaridad entre las generaciones" [COM (2007) 244] o la Comunicación "Un mejor equilibrio en la vida laboral: más apoyo a la conciliación de la vida profesional, privada y familiar" [COM (2008) 635 final]. 
ra de la coordinación de los cuidados y el apoyo a los cuidados informales siguen siendo un auténtico reto.

Por otra parte, en el marco de la Estrategia de Lisboa renovada, junto a estos análisis y propuestas de carácter general con las que se pretende afrontar el reto de los vertiginosos cambios demográficos y socio-económicos, también se han venido desarrollando otras líneas de actuación relevantes para la dependencia - en concreto por lo que afecta a la organización de un sistema público de atención a la dependencia- ya que las iniciativas de la Estrategia en el ámbito económico vienen afectando a los elementos esenciales de estos sistemas, como son el régimen de los servicios, la política de la competencia y la sostenibilidad de la financiación pública.

Estas tres dimensiones, que parecen guardar escasa relación con las políticas de dependencia de los Estados, son los verdaderos condicionantes de su desarrollo. En efecto, esto es así en la medida en que la Unión Europea no puede ejercer una integración positiva imponiendo un determinado modelo de atención a la dependencia sino que, a lo sumo, pueden dictarse documentos como los analizados, en los que se señalan problemas, se ofrece información y se procura influir en el desarrollo homogéneo de las políticas nacionales para aunar sinergias. Sin embargo si se lleva a cabo una integración negativa suprimiendo y armonizando todos aquellos aspectos necesarios para contar con un mercado único de servicios - lo cual condiciona desde el acceso a la prestaciones, a su régimen de prestación-, a lo que se une la armonización de las normas de contratación pública y la erradicación de las medidas adoptadas por los Estados que puedan ser contrarias a la competencia, como son los abusos de posición dominante y las ayudas de Estado — que condicionan el diseño del sistema de atención a la dependencia cuando se articule mediante gestión indirecta - y, por último, se condiciona el alcance de la financiación pública directa de los sistemas nacionales mediante los compromisos adquiridos en la política económica en cuanto a las limitaciones del déficit público.

A falta de una intervención positiva y directa por parte de la Unión Europea sobre los sistemas de atención a la dependencia de los Estados miembros por ausencia de competencias, desde las instancias comunitarias se ha venido incidiendo sobre su configuración esencialmente a través de las iniciativas de la Comisión — no tanto en ejercicio de su iniciativa legislativa cuanto en aplicación de las normas del Tratado (en concreto sobre mercado único y competencia) —, y de la interpretación jurisprudencial que de la misma ha venido desarrollando el Tribunal de Justicia de las Comunidades Europeas. 
2. La inCidencia de la Unión EuRopea EN EL DESARRollo Y APLICACIÓN DE LA DE LA LEY 39/2006 DE PROMOCIÓN DE LA AUTONOMÍA Y ATENCIÓN A LAS PERSONAS EN SITUACIÓN DE DEPENDENCIA

\subsection{La Directiva 2006/123/CE, relativa a los servicios en el mercado interior y su aplicación a los servicios sociales}

El 28 de diciembre de 2006 entró en vigor la Directiva 2006/123/CE del Parlamento Europeo y del Consejo de 12 de diciembre de 2006 relativa a los servicios en el mercado interior (Directiva de Servicios), que debe ser transpuesta antes del 28 de diciembre de 2009.

El objetivo de la Directiva es alcanzar un auténtico mercado único de servicios en la Unión Europea a través de la eliminación de las barreras legales y administrativas que actualmente limitan el desarrollo de actividades de servicios entre Estados Miembros.

Se trata de una Directiva de alcance general — dirigida tanto a los prestadores como a los destinatarios de los servicios, a servicios intermedios para empresas y a servicios finales para los consumidores, y abarcando todas las fases del proceso empresarial, con proyección horizontal — su contenido se configura de forma abstracta sin distinguir entre sectores-, y con un planteamiento global — parte de la inclusión de todos los servicios en general, para excluir posteriormente algunos de ellos-. En todos los servicios incluidos, la Directiva establece un marco jurídico general basado en suprimir de forma prioritaria las barreras que se pueden eliminar rápidamente y, respecto a las demás, plantea iniciar un proceso de evaluación, consulta y armonización complementaria de cuestiones específicas para permitir modernizar de forma progresiva y coordinada los sistemas nacionales de regulación de las actividades de servicios (considerando 7).

El proceso de transposición de la Directiva de Servicios se presenta como una oportunidad para reducir trabas injustificadas o desproporcionadas al acceso y ejercicio de la actividad en determinados sectores, contribuyendo así a un ambicioso programa de simplificación administrativa y de incremento de la transparencia ${ }^{30}$.

Esta singular configuración de la Directiva de Servicios le confiere una enorme capacidad de impacto y transformación de las regulaciones nacionales en su objetivo de alcanzar el mercado único de servicios al fundamentar

30 Para un mayor conocimiento de la Directiva de Servicios y de su proceso de transposición puede consultarse la amplia documentación contenida en la página dedicada a la misma en el Ministerio de Economía y Hacienda (http://www.meh.es) 
su ámbito de aplicación a partir de la inclusión en bloque de todos los servicios, lo que genera una dinámica expansiva. No obstante, esta estructura plantea no pocos problemas relativos, en primer lugar, a la inclusión indiscriminada en su ámbito de aplicación de todo tipo de servicios, lo que hace necesario la exclusión precisa y detallada de aquellos servicios o sectores que por diversas razones han de quedar fuera de su ámbito de aplicación.

Indudablemente se trata de una norma dirigida a transformar de forma radical la ordenación de los servicios en los Estados miembros que, teniendo en cuenta que representan aproximadamente el 70\% del PIB de la Unión, significa modificar la regulación de la mayoría de las actividades económicas dentro de las cuales se encuentran, sorprendentemente los servicios sociales y, por supuesto, los prestados a la dependencia.

No se pretende ahora juzgar la calificación de los servicios sociales como servicios económicos, ni tampoco la bondad de incluirlos en el ámbito de aplicación de la Directiva de Servicios. Partimos de que la aplicación de esta Directiva implica una modificación profunda en la configuración de los sistemas de Servicios Sociales nacionales, por lo que resulta esencial determinar hasta dónde alcanza dicha aplicación, cuestión a la que nos limitaremos en adelante.

En la determinación de la aplicación o no de la Directiva de Servicios a los servicios sociales resulta de especial relevancia el artículo 2.1 j), que debe ser interpretado en el conjunto de los artículos de la Directiva y de sus considerados, así como a luz del resto del Derecho comunitario, y en el contexto del estado actual del proceso de integración comunitario europeo.

El artículo 2 j) señala la exclusión de la Directiva de aquellos servicios sociales en los que concurran acumulativamente las siguientes circunstancias:

A) Debe tratarse de servicios sociales incluidos en los ámbitos materiales señalados en dicho artículo $2 \mathrm{j}$ ), que son los siguientes:

a) Servicios de apoyo a familias y personas temporal o permanentemente necesitadas. El estado de necesidad constituye el elemento determinante ya que se trata de servicios sociales dirigidos a subvenir a aquellos que, de forma individual o colectiva, lo padecen. Las situaciones de necesidad pueden derivarse de diferentes circunstancias que, además, motivan la existencia de servicios sociales específicos. Entre éstos, a tenor de lo dispuesto en el considerando $27^{31}$ de

${ }^{31}$ Considerando 27 de la Directiva: "La presente Directiva no debe afectar a los servicios sociales en los ámbitos de la vivienda, la atención a los niños y el apoyo a familias y personas necesitadas que prestan el Estado a escala nacional, regional o local, o prestadores encargados por el Estado o 
la Directiva, se pueden identificar los servicios sociales cuyo objetivo sea garantizar el apoyo a quienes se hallan, temporal o permanentemente, en un estado particular de necesidad, por una de las siguientes razones:

- Renta: situaciones de necesidad a causa de "unos ingresos insuficientes".

- Riesgo de exclusión: "quienes corren el riesgo de quedar marginados".

- Dependencia: situaciones de necesidad a causa de "una ausencia total o parcial de independencia”.

b) Servicios relativos a la atención de niños. Son todos los servicios destinados a menores de 15 años, conforme a la identificación que se hace en el ámbito comunitario ${ }^{32}$.

c) Servicios relativos a la vivienda social. Son todos aquellos servicios que permiten un acceso a la vivienda a las personas con escasos ingresos $^{33}$.

B) Debe tratarse de servicios sociales que sean objeto de una intervención pública (estatal, autonómica o local) que puede manifestarse en algunas de las siguientes modalidades:

a) Servicios sociales proporcionados por el Estado. Se trata de supuestos de gestión directa de servicios sociales, dentro la que se incluye la prestación del servicio a través de sus propios medios (por ejemplo, una ludoteca municipal), o bien mediante otro sujeto legalmente independiente (in-house provider) ${ }^{34}$.

asociaciones de beneficencia reconocidas como tales por el Estado, con el objetivo de garantizar el apoyo a quienes se hallan, temporal o permanentemente, en un estado particular de necesidad a causa de unos ingresos familiares insuficientes o de una ausencia total o parcial de independencia y a quienes corren el riesgo de quedar marginados. Estos servicios son esenciales para garantizar los derechos fundamentales a la dignidad humana y a la integridad, y son una manifestación de los principios de cohesión social y de solidaridad, y no deben verse afectados por la presente Directiva".

32 El Libro Blanco de la Comisión Europea - Un nuevo impulso para la juventud Europea de 2001 identifica a los jóvenes a los comprendidos entre 15 y 25 años.

33 Según la definición contenida en la Comunicación "Aplicación del programa comunitario de Lisboa Servicios sociales de interés general en la Unión Europea" SEC(2006) 516 $\operatorname{COM}(2006) 177$ final, de 26.4.2006 (p. 4).

${ }^{34}$ Se trata de supuestos en los que los poderes públicos emplean un sujeto con personalidad jurídica propia (pública o privada) bajo su control para prestar el servicio (institutos, fundacio- 
b) Servicios sociales proporcionados por prestadores encargados por el Estado. Se trata de servicios sociales prestados por sujetos privados ajenos a los poderes públicos, independientemente de la existencia o no de ánimo de lucro, mediante intervención por parte de los poderes públicos. La interpretación esta categoría (servicios provistos por "prestadores encargados por el Estado") no resulta sencilla, ya que se basa en una expresión deliberadamente ambigua empleada para llegar a un acuerdo sobre el texto final de la Directiva. A partir de las recomendaciones de la Comisión, los Estados miembros ha concluido que la interpretación de esta cláusula se limita a los servicios sociales prestados a través de cualquiera de las fórmulas de gestión indirecta de servicios públicos (sea a través de concesión, concierto, gestión interesada, arrendamiento o sociedad mixta). En este caso resulta indiferente que se asuma la prestación del servicio con ánimo de lucro o no por parte del sujeto privado que los presta, ya que lo determinante es que se asuma el encargo por parte de cualquiera de los poderes públicos a través de cualquiera de las fórmulas señaladas. Los sujetos privados que suscriben un concierto, acceden una concesión o participan en un modelo de gestión interesada o en una sociedad mixta son encargados por el poder público para prestar el servicio de que se trate y deberán hacerlo de manera obligatoria en las condiciones fijadas.

Por el contrario quedarían incluidos en el ámbito de aplicación de la Directiva los servicios sociales prestados por sujetos privados previa autorización, acreditación, comunicación o registro a los poderes públicos cuando lo hagan con ánimo de lucro. Así se ha interpretado por la Comisión y se ha asumido por los Estados miembros, aunque en verdad dicha inclusión no resulta tan evidente $y$, sobre todo, produce una fragmentación en el tratamiento de los servicios sociales antinatural que puede llegar a afectar al cumplimiento de los objetivos que se prevén para éstos.

La inclusión en este caso no resulta del todo evidente y, sobre todo coherente con el respeto a las competencias de los Estados a la hora de configurar sus propios sistemas de servicios sociales y con la lógica y el espíritu de éstos. De hecho son numerosos los fundamentos jurídicos que, en nuestra opinión, permiten a los Estados miem-

nes, etc.). Las condiciones de esta modalidad son: a) Que la Administración pública ejerza sobre la entidad jurídicamente independiente un control similar al que ejerce sobre sus órganos; b) Que la entidad legalmente independiente ejerza la parte esencial de sus actividades bajo control de la Administración de la que depende (Sentencia Teckal, C-107/98). Así ocurre con los servicios prestados por la Fundación Andaluza de Servicios Sociales. 


\section{bros mantener a los servicios sociales fuera del ámbito de aplicación de la Directiva Servicios ${ }^{35}$.}

35 En primer lugar, la literalidad del artículo no permite alcanzar conclusión alguna ya que tanto la expresión empleada como la traducción de la misma no lo facilitan. Como se ha señalado anteriormente se trata de una expresión pretendidamente oscura ya que se podrían haber empleado en la versión original en inglés otras expresiones más precisas como commissioned (que se ajusta mejor a la traducción en español como "encargado") o entrusted (confiado). Por otra parte la expresión que figura en la versión original en inglés no permite una traducción unívoca, ya que dicha expresión (providers mandated by the State), y, en concreto, el término mandated ha sido traducido en la edición oficial española como "encargado", cuando esta misma expresión contenida en otras normas comunitarias ha recibido otras traducciones distintas, entre las que se incluye la de "autorizados", que se ajusta a la interpretación que aquí se propone.

En segundo lugar, una interpretación sistemática de esta exclusión permite apuntar a un carácter amplio de la misma que abarque todos aquellos supuestos en los que exista una intervención pública (autorizatoria, registral, etc.) sobre servicios sociales prestados por sujetos privados (con o sin ánimo de lucro) dentro de un sistema de servicios sociales ordenado y organizado por los poderes públicos correspondientes. En efecto, el considerando 28 señala que la Directiva " $n o$ afecta a los criterios o condiciones establecidos por los Estados miembros para garantizar que los servicios sociales cumplan efectivamente una función en beneficio del interés público y de la cohesión social. Asimismo, la presente Directiva no debe afectar al principio de servicio universal en los servicios sociales de los Estados miembros". Se trata de una manifestación expresa del respeto hacia la competencia de los Estados miembros para ordenar estos servicios públicos de solidaridad en los que se incluyen, además de los servicios provistos por el Estado, aquellos prestados por sujetos privados con carácter lucrativo, sea bajo el régimen de gestión indirecta o de forma independiente mediante una autorización administrativa en tanto la iniciativa pública en estos ámbitos (al igual que en la salud o la educación) no se limita sino que se admite y se fomenta de manera que concurre (que no compite) con la iniciativa pública complementándola por lo todos los servicios unidos (de prestación pública o privada) forman parte de los sistemas de servicios sociales.

En tercer lugar, la exclusión de los servicios provistos por prestadores encargados por el Estado contenida en artículo 2.2 j) debe considerarse dentro del contexto en el que se desarrolló su elaboración, así como atendiendo a la situación derivada de éste. En concreto, esta exclusión fue introducida en la propuesta modificada presentada por la Comisión tras el rechazo por parte del Parlamento Europeo de la propuesta originaria el 14 de febrero de 2006. Junto a esta exclusión, como consecuencia de la Resolución del Parlamento Europeo, la Comisión inició unos procedimientos específicos para analizar la situación de determinados servicios, en concreto los servicios sociales y los servicios sanitarios que han dado lugar a diversos documentos entre los que destacan la Comunicación "Aplicación del programa comunitario de Lisboa Servicios sociales de interés general en la Unión Europea” COM (2006) 177 final, de 26.4.2006 y la Comunicación "Servicios de interés general, incluidos los sociales: un nuevo compromiso europeo", COM (2007) 724 final, de 20.11.2007. La conexión entre los servicios sociales de interés general y los servicios sociales excluidos en la Directiva es clara, y en este sentido algunos Estados Miembros han manifestado que esta categoría sirve para interpretar de forma amplia la exclusión del artículo 2.2 j) con respecto a los servicios sociales. Además, todo este proceso augura un tratamiento diferenciado de este tipo de servicios que eventualmente puede dar lugar a un régimen jurídico especial propio para estos servicios, lo que avala una interpretación amplia de la exclusión de los servicios sociales de la Directiva de Servicios en la medida que pueden quedar incluidos en una futura directiva sobre los servicios sociales, cuestión sobre la que se han manifestado favorablemente numerosos Estados miembros. 


\section{C) Servicios sociales proporcionados por asociaciones de beneficencia} reconocidas como tales por el Estado. Se trata de servicios sociales provistos por sujetos privados que, independientemente de su forma jurídica (sean asociaciones, fundaciones, órdenes religiosas, organizaciones internacionales, etc.), sean considerados por los poderes públicos como entidades prestadoras de este tipo de servicios sin ánimo de lucro.

Por último, no cabe desconocer los efectos que podría producir una interpretación restrictiva que supusiese la inclusión en el ámbito de aplicación de la Directiva de aquellos servicios sociales prestados por sujetos privados con ánimo de lucro y de forma ajena a toda financiación pública. Es cierto que la aplicación de la Directiva de Servicios no significaría en el caso de estos servicios sociales privados la supresión del régimen de intervención sobre los mismos de los Estados miembros en la medida que son numerosas las excepciones contempladas por razones de interés general a la prohibición de establecer medidas que puedan afectar al libre establecimiento y a la libre prestación de servicios desde otro Estado miembro (como autorizaciones, inscripción en registros, etc.), aunque no todas resulta igual de claras. No obstante también es más cierto que dicha situación deja la intervención de los Estados miembros sobre sus servicios sociales como algo excepcional, lo que plantea la necesidad de romper la presunción de la incompatibilidad que impone con la Directiva, teniendo que justificarse constantemente las medidas dispuestas y estando sometidas a una posible modificación de criterio en cualquier momento (arts. 9, 14 y 16 de la Directiva). Además, en el caso de ser toleradas, la Directiva obliga a asumir las intervenciones equivalentes de otros Estados miembros bajo un sistema que, si bien pretende garantizar dicha equivalencia (art. 9.3 Directiva) (con las dificultades que ellos supone en una Unión ampliada a 27 con Administraciones de muy diversa índole), se diferencia sustancialmente de la armonización existente en otros ámbitos sensibles como la sanidad (o en otros distintos como las telecomunicaciones, el sector eléctrico o los transportes) en los que se impone desde el Derecho comunitario unas condiciones comunes para la intervención a nivel estatal (como en el caso de las autorizaciones nacionales de los medicamentos, por ejemplo), situación que no se reproduce en el ámbito de los servicios sociales al no existir (por ahora) normativa comunitaria específica al respecto (esto es, una Directiva sobre servicios sociales). Por lo demás, el sometimiento de estos servicios sociales prestados independientemente por sujetos privados con ánimo de lucro a las exigencias de la Directiva, daría lugar a una fragmentación en el régimen de los servicios sociales, ya que un mismo centro autorizado (una residencia para personas mayores, por ejemplo) podría llegar a regirse por una normativa distinta en la medida que desarrollase su actividad de forma libre y lucrativa o bien suscribiese un concierto público para la ocupación de determinadas plazas por beneficiarios de prestaciones sociales (incluso en el caso de que fuese una sola de ellas). Eso siempre que no se optase por asimilar el régimen del servicio o centro de que se trate al exigido por aplicación de la Directiva de Servicios, arrastrándose así a todos los servicios sociales (privados o públicos) a su contenido dando lugar a una rebaja en la intervención administrativa en tanto la Directiva encierra un principio de reducción y minimización de la ordenación pública de las actividades de servicio. Con independencia de las elucubraciones que se puedan plantear sobre los resultados de una eventual aplicación de la Directiva de Servicios a estos servicios sociales, lo que resulta indudable es que la inseguridad jurídica que generaría tal hipótesis hace recomendable una interpretación respetuosa con las garantías públicas intrínsecas a los sistemas de servicios sociales que, tal y como reconoce la propia Directiva en su considerando 27, "son esenciales para garantizar los derechos fundamentales a la dignidad humana y a la integridad, y son una manifestación de los principios de cohesión social y de solidaridad, y no deben verse afectados por la presente Directiva”. 


\subsection{La adecuación de los servicios sociales a la normativa comunitaria europea sobre contratación pública y sobre competencia}

Desde hace algunos años se viene desarrollando el debate acerca del alcance en la aplicación del Derecho comunitario europeo a los servicios sociales.

Este debate surge precisamente durante la tramitación de la Directiva Servicios cuando la propuesta del Comisario Bolkestein fue rechazada por el Parlamento europeo debido a la fuerte oposición manifestada en diversos países bajo la amenaza del "fontanero polaco". En la propuesta modificada presentada por la Comisión se incorporó la exclusión de los servicios no económicos de interés general, así como de los servicios sanitarios y de los servicios sociales, y simultáneamente se acordó iniciar de forma paralela y separada una aproximación a nivel comunitario a estos dos sectores, de manera que se completase y compensase dicha exclusión.

En el caso de los servicios sociales, tras un período de consultas, la Comisión publicó en abril de 2006 una Comunicación para enmarcar el debate denominada "Aplicación del programa comunitario de Lisboa. Los servicios sociales de interés general en la Unión Europea" COM(2006) 177 final, con la que dio carta de naturaleza a un subtipo de servicios de interés general dentro de los no económicos, como son los servicios sociales de interés general que reúnen a los servicios legales de protección social (regímenes de Seguridad social obligatorios y complementarios) y todos los servicios propios de la acción social.

De forma simultánea a la adopción por parte de la Comisión de estas propuestas, tuvo lugar la tramitación del Tratado de Lisboa firmado el 13 de diciembre de 2007, al que acompaña un Protocolo referido a los "servicios de interés general" que si bien no pasa de ser una declaración institucional, tiene un significado trascendental. En primer lugar, por incluir por primera vez en el Derecho primario la noción de servicios de interés general (ya que hasta ahora únicamente se hacía referencia a los de carácter económico), y, asimismo, por referirse de forma expresa a los de carácter no económico afirmando que las disposiciones de los Tratados no afectarán en modo alguno a la competencia de los Estados miembros para prestar, encargar y organizar servicios de interés general que no tengan carácter económico.

Más allá de este reconocimiento de la competencia a los Estados para disponer sus servicios no económicos el Protocolo no se pronuncia sobre el problema del tratamiento de estos servicios por el Derecho comunitario, cuestión clave que permanece en manos del Tribunal de Justicia, que es quien determina la compatibilidad de la ordenación estatal con los normas sobre competencia y con el mercado único. 
A esta cuestión se refiere precisamente la Comunicación de la Comisión denominada "Servicios de interés general, incluidos los sociales: un nuevo compromiso europeo", [COM (2007) 725 final] que acompaña a la Comunicación denominada "Un mercado único para la Europa del siglo veintiuno". Esta Comunicación se sitúa en línea de continuidad de las acciones de la Comisión que se remontan a la Comunicación sobre servicios de interés general de 1996, su revisión del año 2000 y el Libro Verde y Blanco de 2003 y 2004 respectivamente.

En esta Comunicación de 2007 se puede apreciar cómo la Comisión reconoce la imposibilidad de dar una respuesta a priori sobre la distinción entre servicios económicos y no económicos, ya que esto requiere un análisis de cada caso particular atendiendo a la realidad específica del Estado miembro, a los modos de prestación de los servicios en función de las condiciones tecnológicas, económicas, sociales e institucionales.

Volvemos en este punto a la Comunicación "Aplicación del programa comunitario de Lisboa. Servicios sociales de interés general en la Unión Europea” [COM (2006) 177 final], ya que es la que más interesa a efectos de considerar la aplicación del Derecho comunitario europeo - y, en concreto, las normas sobre contratación pública y sobre competencia- a los servicios de interés general y, en particular, a los vinculados a la dependencia.

En esta Comunicación se destaca la importancia de los servicios sociales en la Unión, debido a la función esencial que cumplen para alcanzar la cohesión social y al ser un eje primordial en la creación de empleo. En segundo lugar, realiza un completo análisis de los servicios sociales en la Unión, distinguiendo los servicios de protección social y los servicios prestados directamente a la persona mediante ayudas directas. En último lugar realiza un análisis del marco jurídico aplicable a los servicios sociales, atendiendo a la aplicación de las normas del Derecho comunitario; en concreto, de las normas sobre competencia, la aplicación del derecho de la contratación pública y la compatibilidad con las reglas del mercado interior en cuanto a la libre prestación de servicios.

Las dificultades en la determinación exacta del alcance del Derecho comunitario en el ámbito de los servicios sociales de interés general y la trascendencia de dicha aplicación motivó que la Comisión fuera acompañada de dos documentos de trabajo de la propia Comisión relativos a la aplicación respectivamente a la aplicación de las normas de contratación pública y a la apliación de la normativa sobre ayudas de estado: Commission Staff Working Document Frequently asked questions concerning the application of public procurement rules to social services of general interest COM 2007 (725); Commission Staff Working Document Frequently asked questions in relation with Commission Decision of 28 November 2005 on the appli- 
cation of Article 86(2) of the EC Treaty to State aid in the form of public service compensation granted to certain undertakings entrusted with the operation of services of general economic interest, and of the Community Framework for State aid in the form of public service compensation.

Estos documentos ponen en evidencia que existe una firme voluntad por parte de la Comisión por aclarar los límites en las aplicación del Derecho comunitario a los servicios sociales sobre la premisa de que dicha aplicación viene siendo una lógica constante. De algún modo, la Comisión a través de este análisis — que ha sido también objeto de un estudio detallado asimismo por el Comité de Protección Social ${ }^{36}$ —, está generando una dinámica en la que se asume como natural la interferencia del Derecho comunitario en la configuración por parte de los Estados de sus servicios sociales.

En definitiva, debe estarse muy atentos a la evolución de este proceso que, de no verse alterado mediante iniciativas radicales — como sería la aprobación de una Directiva sobre servicios de interés general—, dará lugar a una progresiva permeación del Derecho comunitario en los servicios sociales y, entre otros en los servicios de la dependencia previstos en la LPAP. Mientras esto sea así habrá de estarse a lo dispuesto en la jurisprudencia del Tribunal de Justicia, que ha venido resolviendo cuestiones relacionadas con el alcance de la aplicación de las normas del mercado único y de la competencia a los servicios sociales que resultan insuficientes ya que sólo aportan un criterio fragmentario, ya que no es su función determinar dicho alcance con carácter general; asimismo habrá de tenerse en cuenta las iniciativas de la Comisión que van apuntando la dirección en que se habrá de resolver la cuestión, además de actuar como elementos de softlaw.

\subsection{La sostenibilidad de la financiación pública de los sistemas de protección de la dependencia}

Por último conviene hacer una breve referencia a los elementos que desde las instancias comunitarias condicionan la financiación pública de los servicios sociales. En este sentido, la decisión con respecto al alcance de la financiación pública en los servicios de la dependencia, el recurso a la iniciativa privada y el alcance del copago previsto en la LEPA siguen siendo cuestiones que permanecen en manos exclusivas de los Estados miembros. Sin embargo, no cabe desconocer que los Estados se encuentran condicionados

${ }^{36}$ Los resultado de dicho estudio pueden encontrarse en "Operational conclusions of the Social Protection Committee on the application of community rules to SSIG" SPC 2008/17 final. 
por los compromisos adquiridos con respecto al endeudamiento público y la contención del déficit.

Antes de entrar en el análisis de la trascendencia de las decisiones de política económica de la Unión Europea sobre la configuración de la financiación pública de los sistema de atención a la dependencia, merece la pena señalar las iniciativas que se han desarrollado también desde la Unión en cuanto al análisis y las propuestas de soluciones frente a la sostenibilidad de la finanzas públicas.

Dado el envejecimiento de la población europea, que afecta tanto a los ingresos - que son menores al tener un menor número de población activa - y al gasto - que aumenta ante la necesidad de atender a una mayor población-, los Estados miembros tienen que afrontar el reto de garantizar la sostenibilidad a largo plazo de las finanzas públicas teniendo en cuenta las consecuencias del envejecimiento de la población sobre el presupuesto. Para afrontar dicho reto se vienen dictando documentos como la Comunicación "Sostenibilidad a largo plazo de las finanzas públicas en la Unión Europea" [COM (2006) 574 final], se parte de los retos que plantea el envejecimiento de la población a nivel económico, presupuestario y social, y, en particular, a su incidencia en el crecimiento y mayor presión del gasto público.

En este sentido evalúa las previsiones del gasto público relacionado con la edad a largo plazo y las estrategias presupuestaria de los Estados miembros, estimando un aumento del 4\% hasta el 2050 para la Unión con grandes diferencias en cada uno de los Estados. Así diferencia entre los Estados con alto, medio (entre los que sitúa a España) y bajo nivel de riesgo socioeconómico en función del aumento de los gastos relacionados con la edad a largo plazo, los amplios déficits y el alto nivel de deuda pública.

Para hacer frente a estos retos se propone una estrategia basada en que los Estados alcancen y mantenga situaciones presupuestarias sólidas, reducir cuanto antes el nivel de deuda pública, aumentar las tases de empleo, la aplicación de reformas a las pensiones y a los sistemas de asistencia sanitaria y de asistencia de larga duración garantizando su adecuación y accesibilidad.

Al margen de estos análisis prospectivos que pueden condicionar las decisiones de los Estados miembros a la hora de configurar sus respectivos sistemas de servicios sociales, éstos quedan vinculados por las decisiones adoptadas en el ámbito de la política económica.

A este respecto debe recordarse la vigencia del Pacto de Estabilidad y Crecimiento (PEC) que constituye un marco normativo para la coordinación de las políticas fiscales nacionales dentro de la Unión Económica y Monetaria (UEM). Adoptado mediante Resolución del Consejo Europeo sobre el Pacto de estabilidad y crecimiento (Amsterdam, 17 de junio de 1997) consiste en una supervisión fiscal de los países miembros y un régi- 
men sancionador por el incumplimiento de las condiciones del mismo. De este modo se consiguen mantener unas finanzas públicas saneadas, mediante un componente preventivo y un componente disuasorio ${ }^{37}$.

Para superar el reto que plantea el envejecimiento de la población, y considerando la importancia concedida a la sostenibilidad a largo plazo por la reforma del Pacto llevada a cabo en 2005, se han establecido previsiones presupuestarias a largo plazo para la Unión y se está evaluando y controlando la situación específica de cada Estado miembro (en el informe sobre sostenibilidad figura un análisis global). A estos efectos, la sostenibilidad a largo plazo de la hacienda pública también se tiene en consideración a la hora de evaluar los programas de estabilidad y de convergencia.

No cabe duda que el contenido del Pacto condiciona las decisiones de los Estados miembros a la hora de establecer y configurar sus servicios sociales. Por lo tanto, mientras no resulte modificado a resultas de la crisis económica iniciada en 2008, el Pacto constituye un límite a tener en cuenta en la financiación pública del sistema público de atención a la dependencia previsto en la LEPA.

37 El componente preventivo implica que los Estados miembros deben presentar programas anuales de estabilidad (o de convergencia), en los que indiquen cómo se proponen alcanzar situaciones presupuestarias saneadas a medio plazo, teniendo en cuenta las repercusiones que tendrá el envejecimiento de la población sobre el presupuesto. La Comisión evalúa estos programas y el Consejo emite un dictamen sobre ellos. El componente preventivo incluye dos instrumentos que pueden emplearse para evitar la aparición de déficit "excesivos": el Consejo, partiendo de una propuesta de la Comisión, puede formular un aviso preventivo para evitar la aparición de un déficit excesivo; formulando un asesoramiento rápido, la Comisión puede recomendar a un Estado miembro que respete sus obligaciones derivadas del Pacto de Estabilidad y Crecimiento

La parte disuasoria del Pacto se expresa en el procedimiento de déficit excesivo que se inicia cuando el déficit rebasa el límite del 3\% del PIB fijado en el Tratado. Si se decide que el déficit es excesivo en el sentido del Tratado, el Consejo formula recomendaciones dirigidas al Estado miembro afectado para que éste corrija el déficit excesivo, y establece un plazo para ello. Si éste no cumple las recomendaciones, se prosigue la aplicación del procedimiento de déficit excesivo, que puede implicar la imposición de sanciones al Estado miembro. 


\section{Desarrollo y Evolución del Sistema para la Autonomía y la Atención a la Dependencia}


